\title{
Differences in fish-assemblage structure between fished and unfished atolls in the northern Line Islands, central Pacific
}

\author{
Edward E. DeMartini ${ }^{1, *}$, Alan M. Friedlander ${ }^{2}$, Stuart A. Sandin $^{3}$, Enric Sala ${ }^{4}$ \\ ${ }^{1}$ NOAA Fisheries Service, Pacific Islands Fisheries Science Center, 2570 Dole Street, Honolulu, Hawaii 96822-2396, USA \\ ${ }^{2}$ NOAA, National Ocean Service, National Centers for Coastal Ocean Science-Biogeography Branch and \\ The Oceanic Institute, Makapuu Point/41-202 Kalanianaole Highway, Waimanalo, Hawaii 96795, USA \\ ${ }^{3}$ Center for Marine Biodiversity and Conservation, Scripps Institution of Oceanography, University of California, \\ San Diego, 9500 Gilman Drive, San Diego, California 92093-0202, USA \\ ${ }^{4}$ Centre d'Estudis Avançats de Blanes, Consejo Superior de Investigaciones Científicas, \\ Accés Cala Santa Francesc, 14, 17300 Blanes, Spain
}

\begin{abstract}
We describe the abundance, biomass, size composition, and trophic structure of fish assemblages of shallow (10 m depth) fore reef habitats at 2 US Pacific atolls (Kingman, Palmyra) and 2 Kiribati-owned atolls (Tabuaeran, Kiritimati) in the northern Line Islands. Our characterization spans several coincident gradients (in human habitation and exploitation, latitude, and nutrient upwelling) from uninhabited, presently unfished, and oligotrophic Kingman to relatively densely populated, fished, and equatorially upwelled Kiritimati. Major findings are most consistent with direct effects of extraction on large-bodied predators and indirect effects on lower-level assemblage structure. Fish assemblages at Palmyra and especially Kingman atolls were characterized by high total standing biomass, large average body sizes, a preponderance of apex predators and other piscivorous fishes in an inverted biomass pyramid, few and small planktivorous fishes, and herbivores dominated by non-territorial species. Median body sizes at color change from initial to terminal phase (an index of sex change in parrotfishes) were also small for 4 species of parrotfish at Kingman and Palmyra. Fish assemblages at Tabuaeran and especially Kiritimati atolls had starkly contrasting characteristics: piscivorous and other fisheries-targeted fishes were depauperate, lower-trophic levels dominated fish biomass, planktivorous fishes were larger-bodied and more numerous, territorial herbivores were better represented, and size at maturation in parrotfishes was proportionately larger. Our results show the effects that even modest fishing effort can have on assemblage structure and indicate the importance of reefs like Kingman as increasingly rare relicts of natural coral reefs, providing insights into the natural structure and function of these ecosystems.
\end{abstract}

KEY WORDS: Apex predation - Fisheries extraction - Prey body size distribution · Inverted biomass pyramid $\cdot$ Latitudinal gradient $\cdot$ Upwelling $\cdot$ Body size at sex change $\cdot$ Parrotfishes

\section{INTRODUCTION}

Predation, whether mediated naturally or by human exploitation, exerts a strong direct influence on the survivorship and densities of prey, which can have a considerable influence on prey distribution, behavior, and population dynamics. Predation-based effects have been well documented for fishes on shallow-water coral reefs (e.g. Hixon \& Jones 2005). However, opportunities for observing predation effects continue to diminish; few truly natural and wild ecosystems remain today, including coral reefs and the fish assemblages that conspicuously characterize them. Responses of reef fish prey to predation include, but are not limited to, reductions in 
abundance and shifts in size composition to smaller body sizes (Connell 1998), changes in the sheltering behavior of prey (Sackley \& Kaufman 1996), alterations of interactions among prey species (Almany 2003), increased survivorship of unpreferred prey (Webster \& Almany 2002), and shifts to smaller sizes at sexual maturation and sex change (Platten et al. 2002, Hawkins \& Roberts 2004a, DeMartini et al. 2005).

Experimental demonstration of the effects of predator removal on prey populations and on entire fish assemblages is logistically practical only for small species at very small spatial scales (e.g. on patch reefs). An island-wide comparison of fish assemblages subject to different levels of exploitation by humans is a better alternative to controlled experimentation because it is more commensurate with the scale of the ecosystem and its impacts. Few studies have taken advantage of such natural experiments to address the effects of the reduction of large predators, including sharks, on whole fish food webs. Recently, Friedlander \& DeMartini (2002) documented the differences between unpopulated, near-pristine and largely unexploited northwestern Hawaiian Island (NWHI) atolls and the densely inhabited main Hawaiian Islands (MHI) whose nearshore reef resources are depleted. They found that, in the absence of fishing in the NWHI, large predators like sharks and jacks accounted for $>54 \%$ of total fish biomass, whereas fishing in the MHI reduced top predator biomass to a mere $3 \%$. Controlling for latitude within the expansive $(1500 \mathrm{~km})$ archipelago by restricting evaluation to the 3 northernmost NWHI atolls, DeMartini et al. (2005) observed increases in prey body-size distributions and sizes at sex change for parrotfishes consistent with decreased density of apex predators and increased human extraction of apex predators.

To test the generality of findings from the Hawaiian Islands, we sought another reef fish system that spanned an exploitation gradient, including reefs with even less human disturbance and greater predator biomass than the NWHI, and whose fish assemblage structure is more representative of low-latitude Indo-Pacific reefs. We chose the northern Line Islands in the central Equatorial Pacific, an archipelago comprising 4 atolls and 1 island. The archipelago spans 4.5 degrees of latitude and lies in a distinct biogeographic region from the NWHI. The 4 atolls in the northern Line Islands provide a useful (if not perfectly controlled, see 'Materials and methods') natural experiment of predation effects on coral reefs, analogous to the situation in the NWHI. Dramatic variations in apex predator biomass have been noted across these atolls (Stevenson et al. 2007, Sandin et al. 2008), along with associated changes in the coral, other invertebrate, and algal assemblages (Sandin et al. 2008), and in the microbiota (Dinsdale et al. 2008).
Our general objective here was to evaluate differences in reef fish assemblages across the archipelago and interpret these differences in the context of known natural (climate, upwelling, oceanography) and anthropogenic (fishing) differences among atolls. Our specific goals were, first, to compare the attributes of fish assemblages among the physiographically similar atolls across these interrelated gradients. Assemblage attributes were further compared over the human population-resource gradient along the leeward side of Kiritimati, the atoll with the highest human population density. Contrasts focus on the numbers, biomass, and size structure of each major trophic group of reef fishes, and overall assemblage structure. Second, we evaluated size at color phase (sex) change in protogynous parrotfishes, a major taxon of reef fish prey at these atolls, for which an in situ size-at-maturity metric can index the effects of cropping by predators (DeMartini et al. 2005).

\section{MATERIALS AND METHODS}

Sites. The northern Line Islands, located more than $1500 \mathrm{~km}$ to the SSW of the Hawaiian Archipelago, in the central Equatorial Pacific (Fig. 1), include islands that range from relatively densely populated, where near-shore reef resources are heavily fished, to an uninhabited atoll whose reefs are historically little fished and unfished at present (Sandin et al. 2008). The 2 northernmost Line Islands (Kingman and Palmyra atolls) are US Pacific Island possessions. Palmyra atoll had a US military presence of several thousand servicemen for more than a decade during the 1930s and 1940s associated with WWII, and its lagoon and surrounding reef have suffered from extensive dredging, filling, and causeway construction. There is little documentation of nearshore fishery activity at Palmyra or Kingman since WWII because the atolls were essentially uninhabited. Anecdotal reports suggest essentially no reef fishing, with perhaps occasional smallscale shark extraction for fins. All resource extraction has been formally prohibited since the 2 atolls became US National Wildlife Refuges in 2000. Disturbance by inhabitants is presently minimal at Palmyra (home only to a research field station with 20-person maximum capacity) and non-existent at Kingman (uninhabited). The other 2 islands we surveyed (Tabuaeran [Fanning] and Kiritimati [Christmas] atolls) belong to the Republic of Kiribati. In 2005, estimates of i-Kiribati population sizes were 5100 at Kiritimati and 2500 at Tabuaeran. Fisheries data from Kiritimati and Tabuaeran indicate that subsistence fishing dominates reef activities at each atoll, with only limited commercial extraction of food fish and ornamentals (Sandin et al. 2008). 


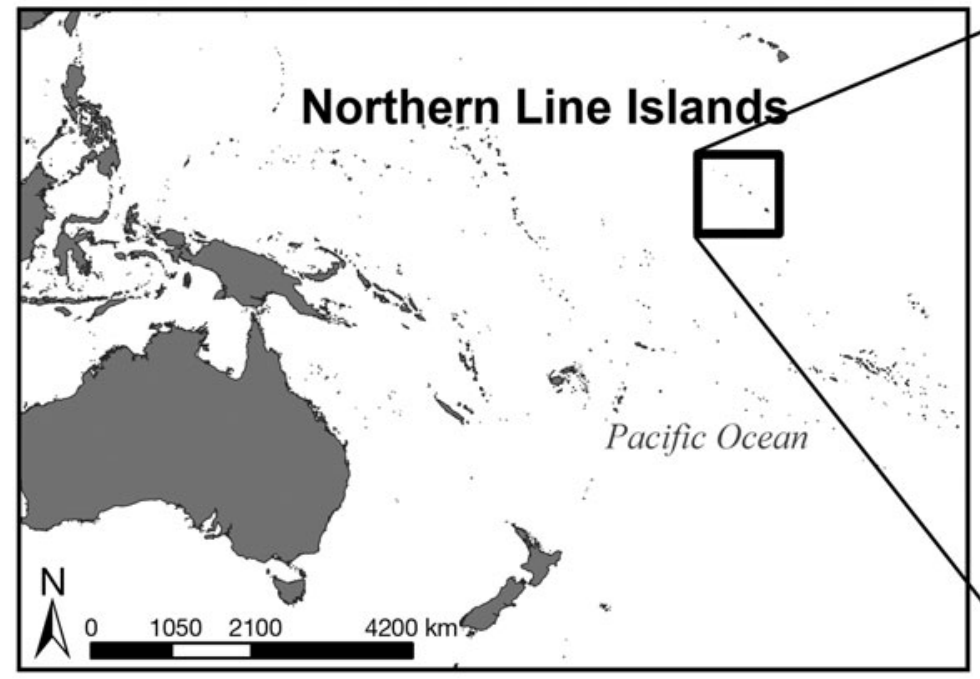

\section{Kingman \\ "Palmyra}

- Teraina

- Tabuaeran
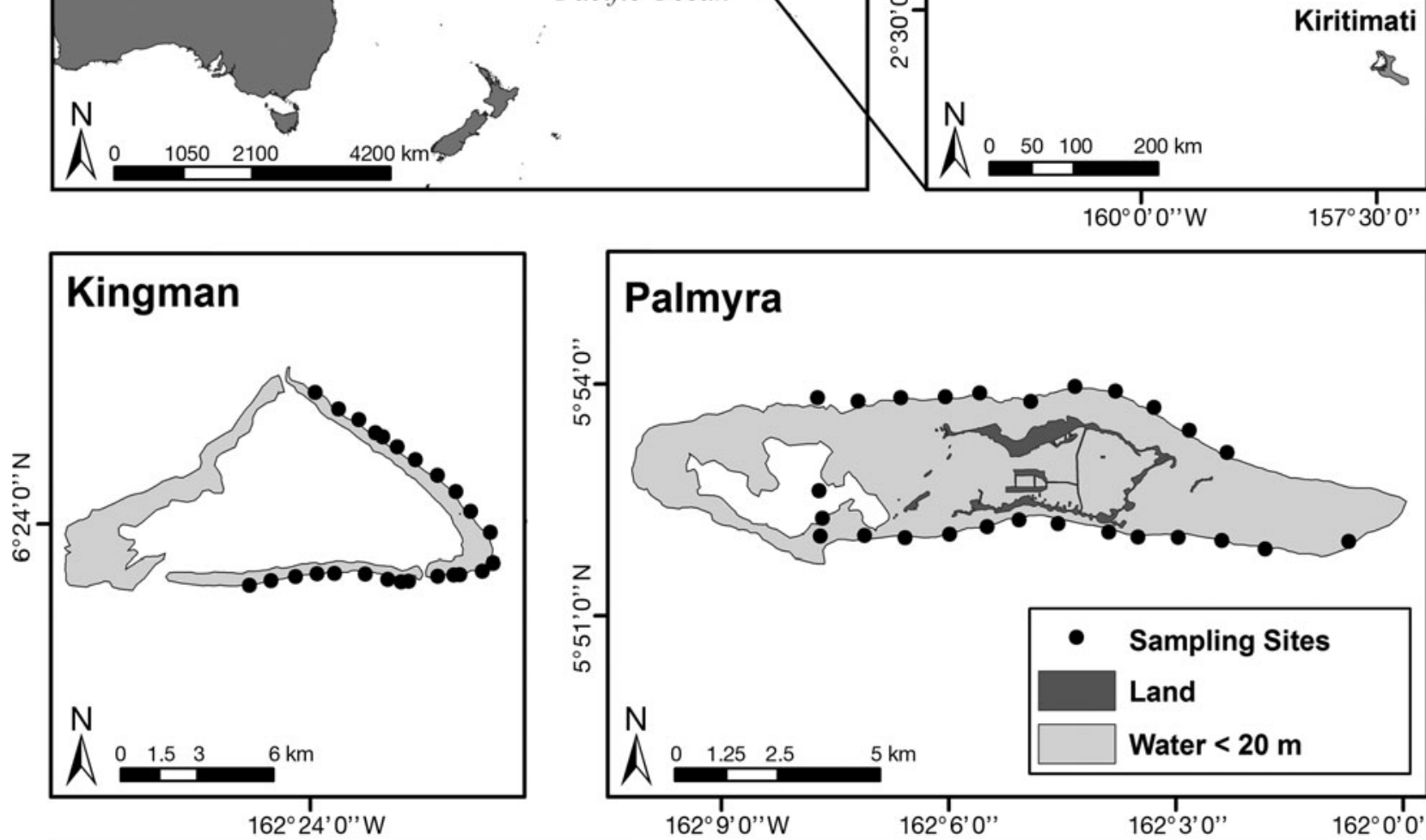

\section{Palmyra}
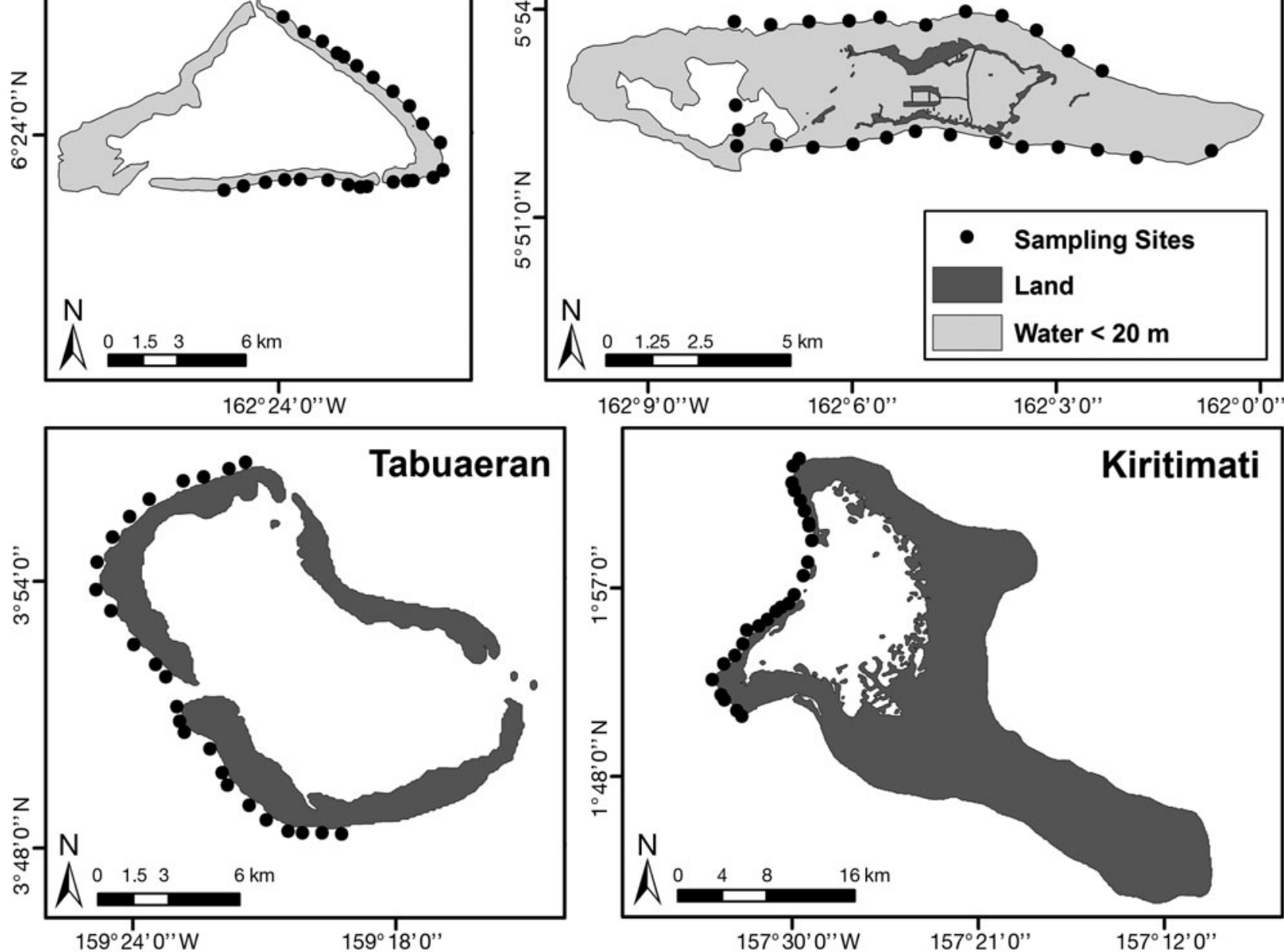

$162^{\circ} 9^{\prime} 0^{\prime \prime} \mathrm{W} \quad 162^{\circ} 6^{\prime} 0^{\prime \prime} \quad 162^{\circ} 3^{\prime} 0^{\prime \prime} \quad 162^{\circ} 0^{\prime} 0^{\prime \prime}$

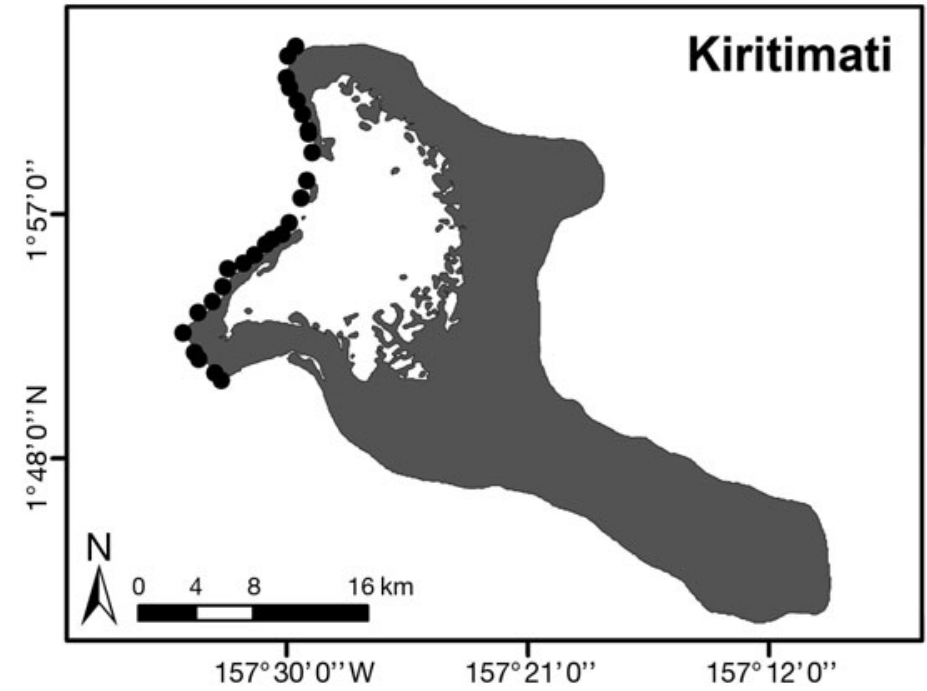

Fig. 1. Four northern atolls in the US (Kingman, Palmyra) and Kiribati Line Islands (Tabuaeran, Kiritimati), showing locations of fore reef stations at which reef fishes were surveyed during 5-30 August 2005 
The main physical differences among the 4 atolls are area of emergent land mass and extent of reef perimeter (Sandin et al. 2008). Levels of human habitation and resource extraction covary among the atolls with variations in geographic and oceanographic gradients. The 4 atolls range from $1.9^{\circ} \mathrm{N}, 157.4^{\circ} \mathrm{W}$ (Kiritimati) to $6.4^{\circ} \mathrm{N}, 162.4^{\circ} \mathrm{W}$ (Kingman). Kiritimati (and, to a lesser extent, Tabuaeran) are bathed by upwelled, cooler, and more nutrient-rich waters of the eastward-flowing South Equatorial Current and the westward-flowing Equatorial Undercurrent. Palmyra and Kingman lie in the region of the eastward-flowing North Equatorial Countercurrent, and their surrounding waters are warmer and more oligotrophic (Sandin et al. 2008, Gove 2008).

Survey and station characteristics. Similar sampling efforts were expended at all atolls: 25 stations each at Kiritimati, Tabuaeran, and Kingman atolls, and 26 stations at Palmyra atoll (Fig. 1). Surveys were restricted to roughly 20 to $30 \mathrm{~km}$ segments of semi-exposed fore reef habitats at each atoll, with stations haphazardly placed approximately $1 \mathrm{~km}$ apart (Fig. 1). At the inhabited atolls, effort was focused around the centers of human habitation. By constraining our surveys to similar extents of surveyable reef perimeter at each atoll (generally leeward), we omitted the windward sectors at Tabuaeran and Kiritimati, the largest 2 atolls. Observations were further restricted by design to the upper fore reef slope, where depths ranged from 8 to $12 \mathrm{~m}$ (mean $10 \mathrm{~m}$ ). Importantly, our estimates cannot be extrapolated to describe fish stocks spanning the entire fore reef at all atolls, but instead provide a relatively controlled snapshot of 1 stratum for comparison across atolls. Surveys were completed at the 4 atolls within consecutive, 5 to $6 \mathrm{~d}$ periods from 5 to 30 August 2005.

In situ methods. Surveys were conducted by 2 teams of paired divers, with the 4 divers rotating between teams to distribute individual biases (Sandin et al. 2008). Teams enumerated all fishes, by species and $5 \mathrm{~cm}$ total length (TL) size-class, encountered within fixed-length $(25 \mathrm{~m})$ strip transects whose widths differed depending on fish body size $(8 \mathrm{~m}$ wide for fishes $\geq 20 \mathrm{~cm}$ and $4 \mathrm{~m}$ for fishes $<20 \mathrm{~cm}$ ). After fish were quantified on transects, the numbers (by $5 \mathrm{~cm} \mathrm{TL}$ ) of terminal phase (TP) parrotfishes were tallied within $\sim 3000 \mathrm{~m}^{2}$ (100 $\mathrm{m}$ long $\times 30 \mathrm{~m}$ wide) areas searched by 1 -way roving diver swims centered on the transect lines.

Data types and statistical analyses. Transects provided the input to generate estimates of species- and size-specific numerical densities (hereafter abundance). Numbers were converted to wet weight biomass using length-weight regression parameters from several sources (Sandin et al. 2008). Species analyzed for density and body size patterns were chosen based on relative biomass and statistical tractability; in particular, species contributing little biomass or that were sporadically distributed were not evaluated.

Comparisons of fish densities and evaluations of size-density relations used additional, either nonparametric or parametric statistics, depending on sampling distributions of the data and their response to logtransformation for homogeneity of variances (Sokal \& Rohlf 1981, Siegel \& Castellan 1988). Analysis routines were applied using SAS v. 9.1 (SAS Institute 2004). Abundance-Biomass Comparisons ( $\mathrm{ABC}$; Warwick \& Clarke 1994) provided complementary metrics for interpreting fish assemblage structure, specifically comparing species-specific abundance and biomass distributions. Nonmetric multi-dimensional scaling (nMDS) and analysis of similarity (ANOSIM; Clarke \& Gorley 2006) were used to evaluate spatial variation among stations and atolls in biomass structure of the assemblages. Biomass size spectra (Rochet \& Trenkel 2003, Graham et al. 2005) were described for all fishes at each atoll using least squares regression to relate $\log _{10}$-transformed biomass density against body length. Size spectra were compared among reefs using least squares analysis of covariance (ANCOVA; proc GLM, SAS Institute 2004).

The criterion for significance of all tests was $p=0.05$, adjusted where necessary for multiple comparisons by the Bonferroni correction $(p=0.05 / \mathrm{m})$, where $\mathrm{m}$ is the number of comparisons within the series (Manly 1991).

\section{RESULTS}

\section{Total biomass and abundance}

Fish biomass and abundance patterns (Sandin et al. 2008) provide context for the analyses that follow. Total reef fish biomass declined monotonically from Kingman, across Palmyra and Tabuaeran, to Kiritimati, ranging 4 -fold from a high of $5.3 \mathrm{mt} \mathrm{ha}^{-1}$ at Kingman to a low of $1.3 \mathrm{mt} \mathrm{ha}^{-1}$ at Kiritimati. Large apex predators and other piscivores dominated biomass (grand mean $62 \%$ of total) among all atolls, but the standing biomass of piscivores was 15 -fold greater at Kingman, and more than 5-fold greater at Palmyra, than at Tabuaeran-Kiritimati. Piscivores alone constituted $85 \%$ of the total biomass at Kingman and $65 \%$ at Palmyra, but contributed less than one-quarter at Tabuaeran (21\%) and Kiritimati (19\%). In contrast, total fish abundance decreased from Kiritimati to Palmyra-Kingman (Table 1).

$\mathrm{ABC}$ curves provide insights into how numbers and biomass were distributed among species. When total biomass and abundance (numbers) were each ranked cumulatively by species, the resulting patterns differed 
Table 1. Summary results of statistical tests evaluating differences among atolls for biomass or abundance and for body size, for trophic categories and statistically tractable component species of fishes encountered at Kingman, Palmyra, Tabuaeran, and Kiritimati atolls surveyed during 5-30 August 2005. A posteriori contrasts are Bonferroni (Dunn) and Gabriel's STP tests for parametric and nonparametric ANOVAs, respectively, and pair-wise chi-squared tests for $k$-sample median tests. TP: terminal phase; ns: not significant; KIN: Kingman; PAL: Palmyra; TAB: Tabuaeran; KIR: Kirimati

\begin{tabular}{|c|c|c|c|}
\hline Category or species & Test statistic & $\mathrm{p}$ & Contrast \\
\hline \multicolumn{4}{|c|}{ Biomass (or abundance, as noted) comparisons among atolls } \\
\hline Total fishes & $F_{3,97}=27.6^{\mathrm{b}}$ & $<0.0001$ & $\mathrm{KIN}>\mathrm{PAL}=\mathrm{TAB}=\mathrm{KIR}$ \\
\hline Total fishes - abundance & $F_{3,97}=69.2^{\mathrm{b}}$ & $<0.0001$ & $\mathrm{KIR}>\mathrm{TAB}>\mathrm{KIN}=\mathrm{PAL}$ \\
\hline Tertiary consumers ${ }^{\mathrm{a}}$ & $F_{3,97}=77.9^{\mathrm{b}}$ & $<0.0001$ & $\mathrm{KIN}>\mathrm{PAL}>\mathrm{TAB}=\mathrm{KIR}$ \\
\hline Reef sharks & $\chi^{2}=75.3^{c}$ & $<0.0001$ & $\mathrm{KIN}>\mathrm{PAL}>\mathrm{TAB}=\mathrm{KIR}$ \\
\hline Twinspot snapper & $\chi^{2}=72.1^{c}$ & $<0.0001$ & $\mathrm{KIN}=\mathrm{PAL}>\mathrm{TAB}>\mathrm{KIR}$ \\
\hline Peacock hind & $F_{3,97}=10.8^{\mathrm{b}}$ & $<0.0001$ & $\mathrm{KIN}=\mathrm{PAL}=\mathrm{TAB}>\mathrm{KIR}$ \\
\hline Darkfin hind & $F_{3,97}=19.4^{\mathrm{b}}$ & $<0.0001$ & $\mathrm{KIR} \geq \mathrm{TAB} \geq \mathrm{PAL}>\mathrm{KIN}$ \\
\hline Humpback snapper & $\chi^{2}=8.05^{c}$ & $0.045 \mathrm{~ns}$ & $\mathrm{PAL}>\mathrm{KIN}=\mathrm{TAB}>\mathrm{KIR}$ \\
\hline Bluestriped snapper & $\chi^{2}=47.4^{c}$ & $<0.0001$ & $\mathrm{TAB}>\mathrm{KIR}$ \\
\hline Blackside hawkfish & $F_{3,97}=33.3^{\mathrm{b}}$ & $<0.0001$ & $\mathrm{KIR}=\mathrm{TAB}>\mathrm{PAL}=\mathrm{KIN}$ \\
\hline Halfspotted hawkfish & $F_{3,97}=3.23^{\mathrm{b}}$ & 0.025 & $\mathrm{TAB} \geq \mathrm{KIN}=\mathrm{PAL}=\mathrm{KIR}$ \\
\hline Secondary consumers & $F_{3,97}=7.15^{\mathrm{b}}$ & 0.0002 & $\mathrm{KIR}=\mathrm{TAB} \geq \mathrm{KIN}=\mathrm{PAL}$ \\
\hline Benthivores & $F_{3,97}=18.5^{\mathrm{b}}$ & $<0.0001$ & $\mathrm{KIR}=\mathrm{TAB}>\mathrm{PAL}=\mathrm{KIN}$ \\
\hline Benthivores - abundance & $F_{3,97}=68.1^{\mathrm{b}}$ & $<0.0001$ & $\mathrm{KIR}>\mathrm{TAB}>\mathrm{PAL}=\mathrm{KIN}$ \\
\hline Planktivores & $F_{3,97}=6.09^{\mathrm{b}}$ & $<0.001$ & $\mathrm{KIR}=\mathrm{TAB}=\mathrm{KIN}>\mathrm{PAL}$ \\
\hline Planktivores - abundance & $F_{3,97}=48.6^{\mathrm{b}}$ & $<0.0001$ & $\mathrm{KIR}>\mathrm{TAB}>\mathrm{KIN}=\mathrm{PAL}$ \\
\hline Primary consumers & $F_{3,97}=8.41^{\mathrm{b}}$ & $<0.0001$ & $\mathrm{TAB}>\mathrm{PAL}=\mathrm{KIR}=\mathrm{KIN}$ \\
\hline Detritivores & $F_{3,97}=5.80^{\mathrm{b}}$ & 0.001 & $\mathrm{TAB}=\mathrm{PAL} \geq \mathrm{KIN}=\mathrm{KIR}$ \\
\hline Non-territorial herbivores & $F_{3,97}=4.15^{\mathrm{b}}$ & 0.008 & $\mathrm{TAB}=\mathrm{PAL} \geq \mathrm{KIR} \geq \mathrm{KIN}$ \\
\hline Territorial surgeonfish & $F_{3,97}=4.20^{\mathrm{b}}$ & 0.008 & $\mathrm{TAB}=\mathrm{KIN}=\mathrm{PAL}>\mathrm{KIR}$ \\
\hline Territorial surgeonfish - abundance & $F_{3,97}=11.3^{\mathrm{b}}$ & $<0.0001$ & $\mathrm{KIN}=\mathrm{TAB}=\mathrm{PAL}>\mathrm{KIR}$ \\
\hline Territorial damselfish & $F_{3,97}=10.2^{\mathrm{b}}$ & $<0.0001$ & $\mathrm{KIR} \geq \mathrm{PAL} \geq \mathrm{TAB}=\mathrm{KIN}$ \\
\hline Territorial damselfish — abundance & $F_{3,97}=8.90^{\mathrm{b}}$ & $<0.0001$ & $\mathrm{KIR} \geq \mathrm{PAL} \geq \mathrm{TAB}=\mathrm{KIN}$ \\
\hline \multicolumn{4}{|l|}{ Body size comparisons among atolls } \\
\hline Twinspot snapper & $\chi^{2}=78.6^{\mathrm{d}}$ & $<0.0001$ & $\mathrm{KIN}=\mathrm{PAL}=\mathrm{TAB}>\mathrm{KIR}$ \\
\hline Peacock hind & $\chi^{2}=0.22^{\mathrm{d}}$ & 0.64 & $\mathrm{KIN}=\mathrm{KIR}=\mathrm{PAL}=\mathrm{TAB}$ \\
\hline Darkfin hind & $\chi^{2}=0.91^{\mathrm{d}}$ & 0.34 & $\mathrm{KIN}=\mathrm{PAL}=\mathrm{TAB}=\mathrm{KIR}$ \\
\hline Humpback snapper & $\chi^{2}=7.6^{d}$ & 0.0005 & $\mathrm{TAB}>\mathrm{KIN}=\mathrm{PAL}=\mathrm{KIN}$ \\
\hline Bluestriped snapper & $-\mathrm{e}$ & 0.0065 & TAB $>$ KIR \\
\hline Benthivores & $\chi^{2}=67.9^{\mathrm{d}}$ & $<0.0001$ & $\mathrm{KIR}=\mathrm{PAL}>\mathrm{KIN}=\mathrm{TAB}$ \\
\hline Planktivores & $\chi^{2}=3967.5^{\mathrm{d}}$ & $<0.0001$ & $\mathrm{KIR}>\mathrm{TAB}>\mathrm{KIN}>\mathrm{PAL}$ \\
\hline Planktivores — coincident spp. only & $\chi^{2}=1100.3^{d}$ & $<0.0001$ & $\mathrm{TAB}>\mathrm{KIR}>\mathrm{KIN}>\mathrm{PAL}$ \\
\hline Primary consumers & $\chi^{2}=887.8^{\mathrm{d}}$ & $<0.0001$ & $\mathrm{TAB}>\mathrm{KIN}=\mathrm{PAL}>\mathrm{KIR}$ \\
\hline Detritivores & $F_{3,97}=3.29^{f}$ & $0.024 \mathrm{~ns}$ & $\mathrm{PAL} \geq \mathrm{TAB}=\mathrm{KIN} \geq \mathrm{KIR}$ \\
\hline Non-territorial herbivores & $F_{3,97}=7.94^{\mathrm{f}}$ & $<0.0001$ & $\mathrm{KIN}=\mathrm{PAL} \geq \mathrm{TAB}=\mathrm{KIR}$ \\
\hline Territorial surgeonfish & $F_{3,93}=26.9^{f}$ & $<0.0001$ & $\mathrm{KIR}>\mathrm{TAB}>\mathrm{KIN}=\mathrm{PAL}$ \\
\hline Territorial damselfish & $F_{3,58}=8.23^{f}$ & $<0.0001$ & $\mathrm{KIR} \geq \mathrm{TAB}=\mathrm{PAL}=\mathrm{KIN}$ \\
\hline Bullethead parrotfish, TP & $\chi^{2}=300.5^{\mathrm{d}}$ & $<0.0001$ & $\mathrm{KIR}>\mathrm{TAB}>\mathrm{PAL}=\mathrm{KIN}$ \\
\hline Bridled parrotfish, TP & $\chi^{2}=114.2^{\mathrm{d}}$ & $<0.0001$ & $\mathrm{KIR}>\mathrm{TAB}>\mathrm{KIN}>\mathrm{PAL}$ \\
\hline Tricolor parrotfish, TP & $\chi^{2}=28.0^{\mathrm{d}}$ & $<0.0001$ & $\mathrm{KIR}>\mathrm{PAL}=\mathrm{KIN}=\mathrm{TAB}$ \\
\hline Redlip parrotfish, TP & $\chi^{2}=38.8^{d}$ & $<0.0001$ & $\mathrm{KIR}=\mathrm{TAB}>\mathrm{KIN}=\mathrm{PAL}$ \\
\hline 4 species of parrotfish, all sizes & $\chi^{2}=115.6^{d}$ & $<0.0001$ & $\mathrm{KIR}>\mathrm{TAB}=\mathrm{PAL}=\mathrm{KIN}$ \\
\hline \multicolumn{4}{|c|}{ a Apex predators and other piscivorous fishes } \\
\hline \multirow{2}{*}{\multicolumn{4}{|c|}{${ }^{b}$ Parametric 1-way ANOVA on either raw or log-transformed data, as appropriate }} \\
\hline \multirow{2}{*}{\multicolumn{4}{|c|}{$\begin{array}{l}\text { 'Kruskal-Wallis 1-way ANOVA on ranks } \\
{ }^{\mathrm{d}} k \text {-sample median test (Siegel \& Castellan 1988) }\end{array}$}} \\
\hline & & & \\
\hline \multicolumn{4}{|l|}{${ }^{\mathrm{e}}$ Fisher's exact test } \\
\hline \multicolumn{4}{|c|}{ fParametric 1 -way ANOVA on log-transformed mean body mass } \\
\hline
\end{tabular}

greatly among atolls. At Kingman, relatively few species overwhelmed the biomass pattern (Fig. 2A). At Palmyra (Fig. 2B), more species contributed strongly to overall biomass; at Tabuaeran (Fig. 2C) and especially at Kiritimati (Fig. 2D), biomass was broadly distributed among a much greater number of species. The relative position of the numbers and biomass curves reversed between Kingman-Palmyra and Tabuaeran-Kiritimati because the biomass curves differed among atolls, whereas the numbers curves basically did not. Despite 


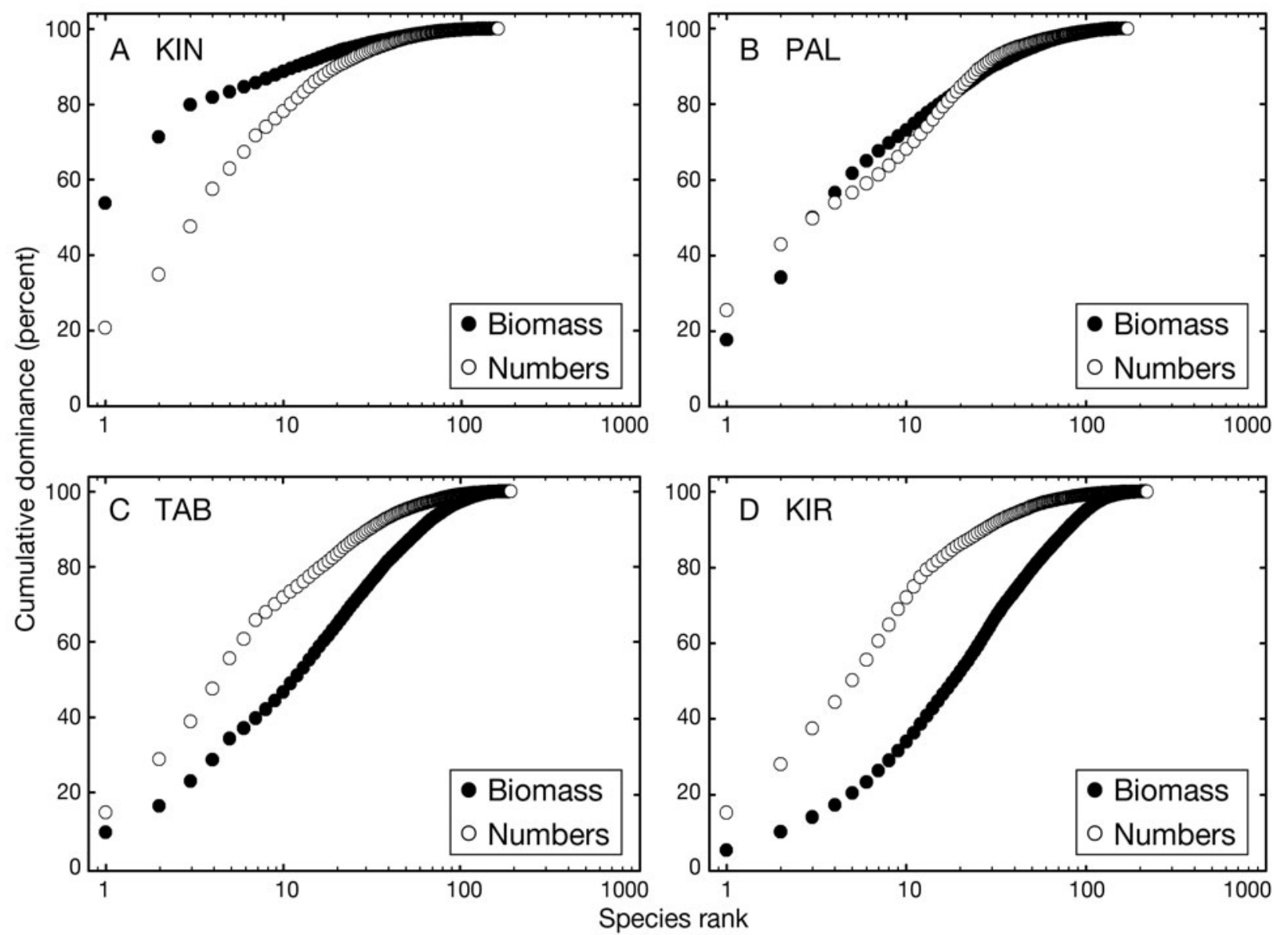

Fig. 2. Abundance-biomass comparison curves relating predator and prey numbers and biomass, illustrating the contrasting numbers versus biomass patterns at (A) Kingman, (B) Palmyra, (C) Tabuaeran, and (D) Kiritimati atolls. Numbers and biomass are accumulated by species independently ranked by the respective metric

the small sample size of only 4 atolls, the $W$-statistic representing the magnitude of separation between abundance and biomass curves declined monotonically from Kingman to Kiritimati (Spearman's rank correlation: $\left.\mathrm{r}_{\mathrm{s}}=1.0 ; \mathrm{p}<0.001\right)$.

Size spectra both complement and reinforce the ABC analyses. Regressions of size-specific biomass densities (of all species pooled) on body length class revealed marked differences among atolls in the influence of large-bodied fishes: regressions of biomass became linear, hence tractable, after data were transformed to their logarithms, but slopes were heterogeneous if Kiritimati was included (1-way ANCOVA: reject $H_{0}$ : no atoll $\times$ size interaction; $F_{3,86}=11.64 ; \mathrm{p}<$ 0.0001; Fig. 3). If re-evaluated for just Kingman, Palmyra, and Tabuaeran, however, slopes become homogeneous ( $\mathrm{p}=0.21)$ and intercepts differed (1-way ANCOVA; reject $H_{0}$ : no atoll effect; $F_{2,77}=4.62 ; \mathrm{p}=$ 0.012), with Kingman and Palmyra indistinguishable but both greater than Tabuaeran (Fig. 3), reflecting the greater mid-point elevations of the biomass curves (higher intercepts representing greater standardized biomass densities) at the 2 unfished atolls. Differences among all atolls except Kiritimati disappeared if either reef sharks $(p=0.46)$ or twinspot snapper $(p=0.075)$ were excluded from the analyses. Thus, the ABC and size spectra analyses together indicate that few individuals of few taxa of large-bodied fishes dominated biomass at Kingman-Palmyra. In contrast, abundance was dictated by a greater number of taxa than was biomass (but still by relatively few species overall) and was represented by numerous individuals of smallbodied fishes that were more dominant at Tabuaeran and (especially) Kiritimati.

\section{Stocks and body sizes of piscivores}

Several species of sharks (grey reef shark Carcharhinus amblyrhynchos, blacktip reef shark C. melanopterus, and whitetip reef shark Triaenodon obesus) and twinspot snapper Lutjanus bohar dominated pisci- 


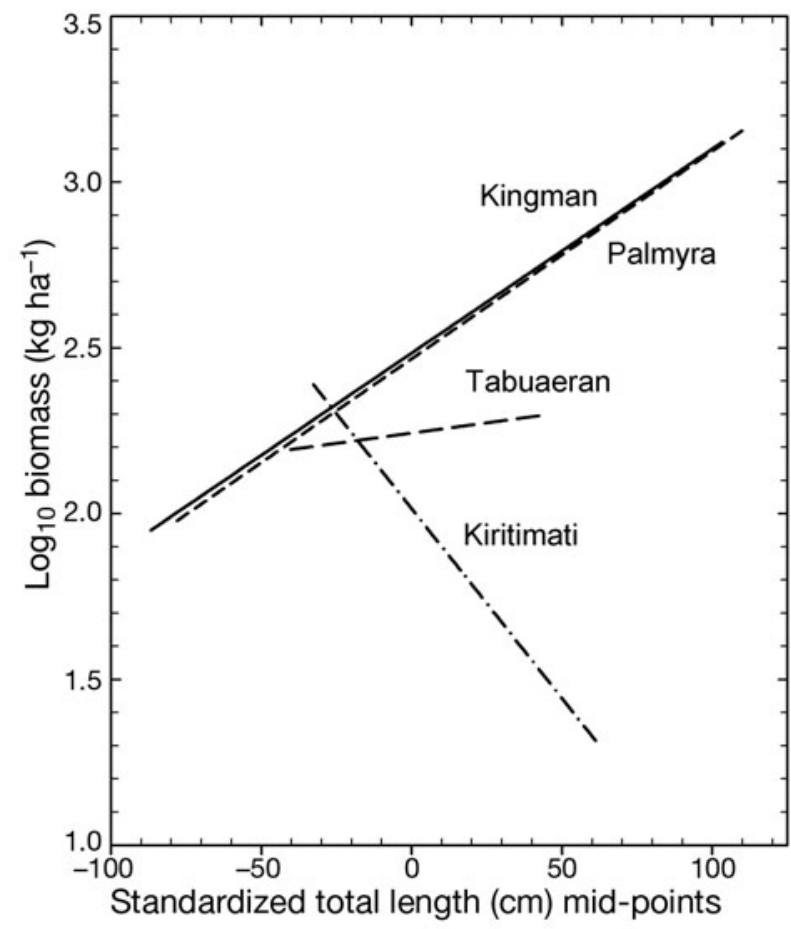

Fig. 3. Biomass size spectra for the aggregate of all fish taxa surveyed at Kingman, Palmyra, Tabuaeran, and Kiritimati atolls

vore biomass at Kingman and Palmyra. Sharks contributed 74 and $57 \%$ to all piscivores and 62 and $37 \%$ to total reef fish biomass at these 2 respective atolls but were trivially present at Tabuaeran and virtually if not actually absent at Kiritimati (Table 1, Fig. 4). L. bohar-a conspicuously aggressive teleost and recognized apex predator (Kulbicki et al. 2005) - comprised a sizable fraction (20\%) of all piscivore biomass at Kingman and Palmyra. Estimated absolute biomass was skewed among atolls, however, with $L$. bohar contributing upwards of $0.8 \mathrm{mt} \mathrm{ha}^{-1}$ at the 2 unexploited atolls but strikingly less $\left(<0.1 \mathrm{mt} \mathrm{ha}^{-1}\right)$ at the 2 fished atolls (Fig. 4, Table 1). The among-atoll differences in total piscivore biomass were driven by $L$. bohar as well as reef sharks; patterns remained highly significant and qualitatively the same as those for total piscivore biomass if either sharks or $L$. bohar were excluded, but differences among atolls disappeared $(p=0.64)$ if both of these taxa were simultaneously excluded from analysis.

The body length distribution of twinspot snapper also contrasted greatly among atolls, with many large (up to $70 \mathrm{~cm}$ TL and $6 \mathrm{~kg}$; median length and weight: $38 \mathrm{~cm}$ TL and $1.2 \mathrm{~kg}$ ) individuals present at Kingman and Palmyra; fewer but similarly sized fish present at Tabuaeran; and very few, considerably smaller fish at Kiritimati (median $13 \mathrm{~cm}$ TL and $90 \mathrm{~g}$; Table 1, Fig. 5). Only 3 (2\%) of the twinspot snapper individuals tallied at Kiritimati were $>40 \mathrm{~cm}$, the estimated length at sexual maturity of this species (Fig. 5). Interestingly, small juvenile twinspot snapper $<10 \mathrm{~cm}$ TL accounted for $38 \%$ (52/135) of the total tally of this species at Kiritimati, but only a single juvenile-sized individual was encountered out of the 1887 total counted on the fore reef at the other 3 atolls pooled.

For all piscivores, the pattern of size distribution differences among atolls generally resembled that for twinspot snapper except that values were intermediate at Tabuaeran (Fig. 6a-d). Relatively few species of lesser piscivores (6 of the 7 tractable species, out of approximately 50 total species) contributed to a pattern of differences in relative abundance and body size across atolls whose net effect was a greater abundance and biomass of lesser carnivores at TabuaeranKiritimati nested within an overall decline in the biomass and average body size of piscivores from Kingman to Kiritimati. Among a suite of small- to large-bodied epinepheline groupers (Serranidae), the peacock hind Cephalopholis argus, a relatively largebodied species (to $60 \mathrm{~cm}$ TL) that is targeted by the fishery at Kiritimati (S. Walsh unpubl.), was less prevalent there $\left(16 \pm 4[\mathrm{SE}] \mathrm{kg} \mathrm{ha}^{-1}\right)$ than at Kingman $(48 \pm$ $8 \mathrm{~kg} \mathrm{ha}^{-1}$ ), although it was not smaller-bodied. Con-
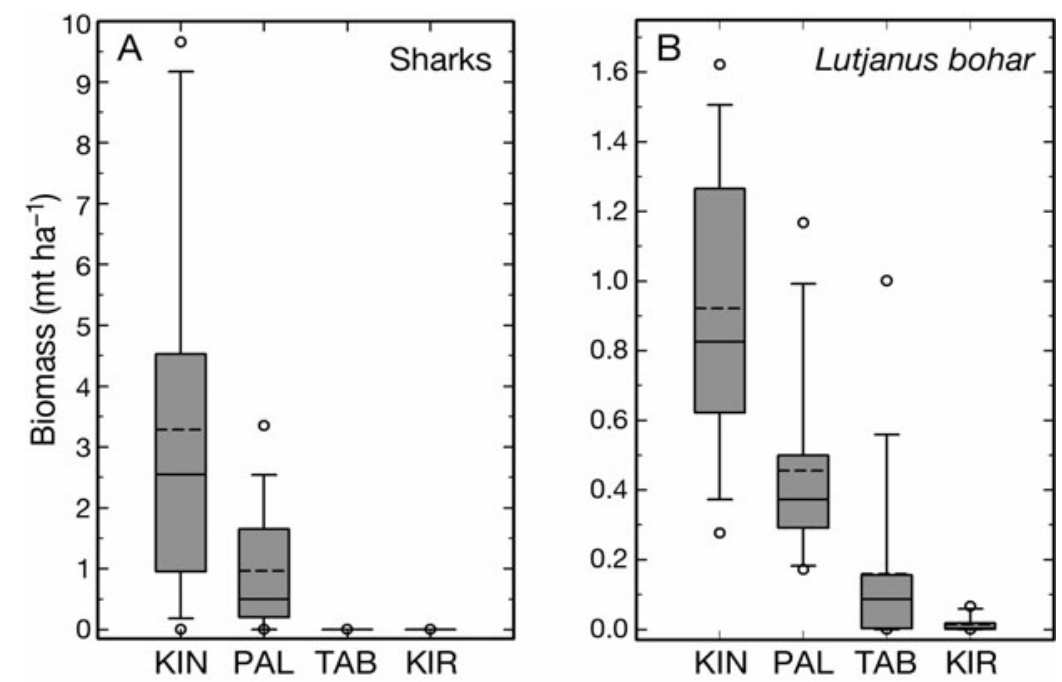

Fig. 4. Biomass estimates for major apex predators at each of the 4 atolls surveyed, showing median (solid horizontal line), quartiles (box), 10th and 90th percentiles (whiskers), 5th and 95th percentiles (circles), and mean (dashed line). (A) aggregate of 3 reef shark species (grey, whitetip, and blacktip) and (B) twinspot snapper Lutjanus bohar. KIN: Kingman; PAL: Palmyra; TAB: Tabuaeran; KIR: Kiritimati 


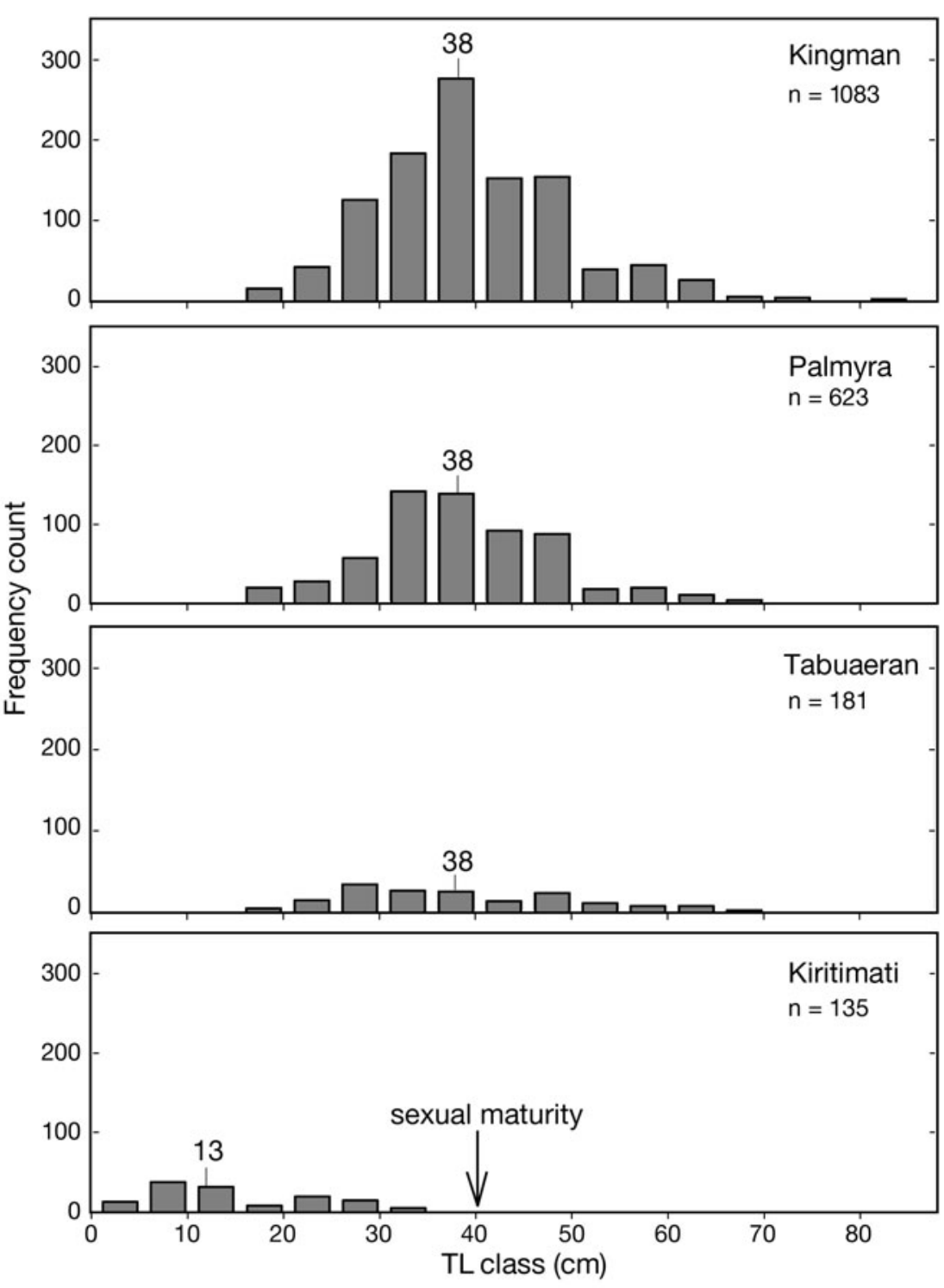

Fig. 5. Lutjanus bohar. Body size frequency distributions of twinspot snapper surveyed at each of the 4 atolls. Numbers above bars: median body lengths. The grand median body length of this snapper was $38 \mathrm{~cm}$ total length (TL). Note that nearly the entire size distribution at leeward Kiritimati stations is smaller than the estimated body size at sexual maturity

versely, a small-bodied (to $25-30 \mathrm{~cm} \mathrm{TL}$, and less targeted) species, the darkfin hind C. urodeta, was more abundant at Kiritimati $\left(63 \pm 8 \mathrm{~kg} \mathrm{ha}^{-1}\right)$ than at Kingman $\left(8 \pm 1 \mathrm{~kg} \mathrm{ha}^{-1}\right)$ but was equal-sized (Table 1$)$. The biomass of a larger-bodied (to $50 \mathrm{~cm}$ TL) lutjanid, the humpback snapper Lutjanus gibbus, was greater at Palmyra $\left(35 \mathrm{~kg} \mathrm{ha}^{-1}\right)$ than at Kiritimati $\left(0.4 \mathrm{~kg} \mathrm{ha}^{-1}\right)$, and the species attained slightly larger size (38 versus $33 \mathrm{~cm}$ ) at Tabuaeran. Biomass of a small-bodied (to $30 \mathrm{~cm}$ TL) species, the bluestriped snapper L. kasmira, was $>60$-fold greater at Kiritimati than elsewhere (Table 1) and was dominated by juvenile-sized individ- uals $(<10 \mathrm{~cm}$ TL) there. Bluestriped snapper were absent on transects at both Kingman and Palmyra, and juvenile humpback snapper were encountered only at Kiritimati.

Consistent patterns extended beyond targeted serranids and snappers to lesser piscivores that were not targeted by fishers. One species (the blackside hawkfish Paracirrhites forsteri, to 20-25 cm TL) was 8 times more abundant at Kiritimati-Tabuaeran $\left(257 \pm 20\right.$ fish $\left.\mathrm{ha}^{-1}\right)$ than at Palmyra-Kingman $\left(31 \pm 6\right.$ fish $\left.\mathrm{ha}^{-1}\right)$. Another slightly larger (to $30 \mathrm{~cm}$ TL) cirrhitid (the halfspotted hawkfish $P$. hemistictus) was more than twice as abundant at Tabuaeran $(73 \pm 13$ fish $\mathrm{ha}^{-1}$ ) than at the other 3 atolls (29 \pm 4 fish $\mathrm{ha}^{-1}$; Table 1).

\section{Densities and body sizes of non- piscivorous fishes}

The biomass of non-piscivorous, lower-trophic level consumers varied less among atolls than did that of piscivores. The biomass of all primary consumers (mostly herbivores, but including some detritivorous acanthurids) was about one-third greater at Tabuaeran $\left(0.7 \mathrm{mt} \mathrm{ha}^{-1}\right)$ than at the other atolls (0.5 mt ha- ${ }^{-1}$; Fig. 7). The body sizes of primary consumers were largest at Tabuaeran, smallest at Kiritimati, and similarly intermediate at Kingman and Palmyra (Table 1, Fig. 8). Stronger patterns emerged for primary consumers when data were partitioned into detritivores $(32 \%$ of primary consumer biomass, consisting of Ctenochaetus spp. and a minority of Acanthurus spp. surgeonfishes) and herbivores (68\% of all primary consumer biomass) with the latter distinguished as territorial and non-territorial species (Fig. 7). Among-atoll patterns in the biomass and body size of territorial herbivores (three species of acanthurids, $85 \%$ by biomass being goldrim surgeonfish $A$. nigricans; and 2 species of pomacentrids, $96 \%$ by biomass being golden gregory Stegastes aureus) differed oppositely from patterns for non-territorial herbivores (Table 1, Fig. 7). Both taxa of territorial herbivores were larger-bodied at Kiritimati. Among-atoll patterns in abundance and biomass differed between territorial 


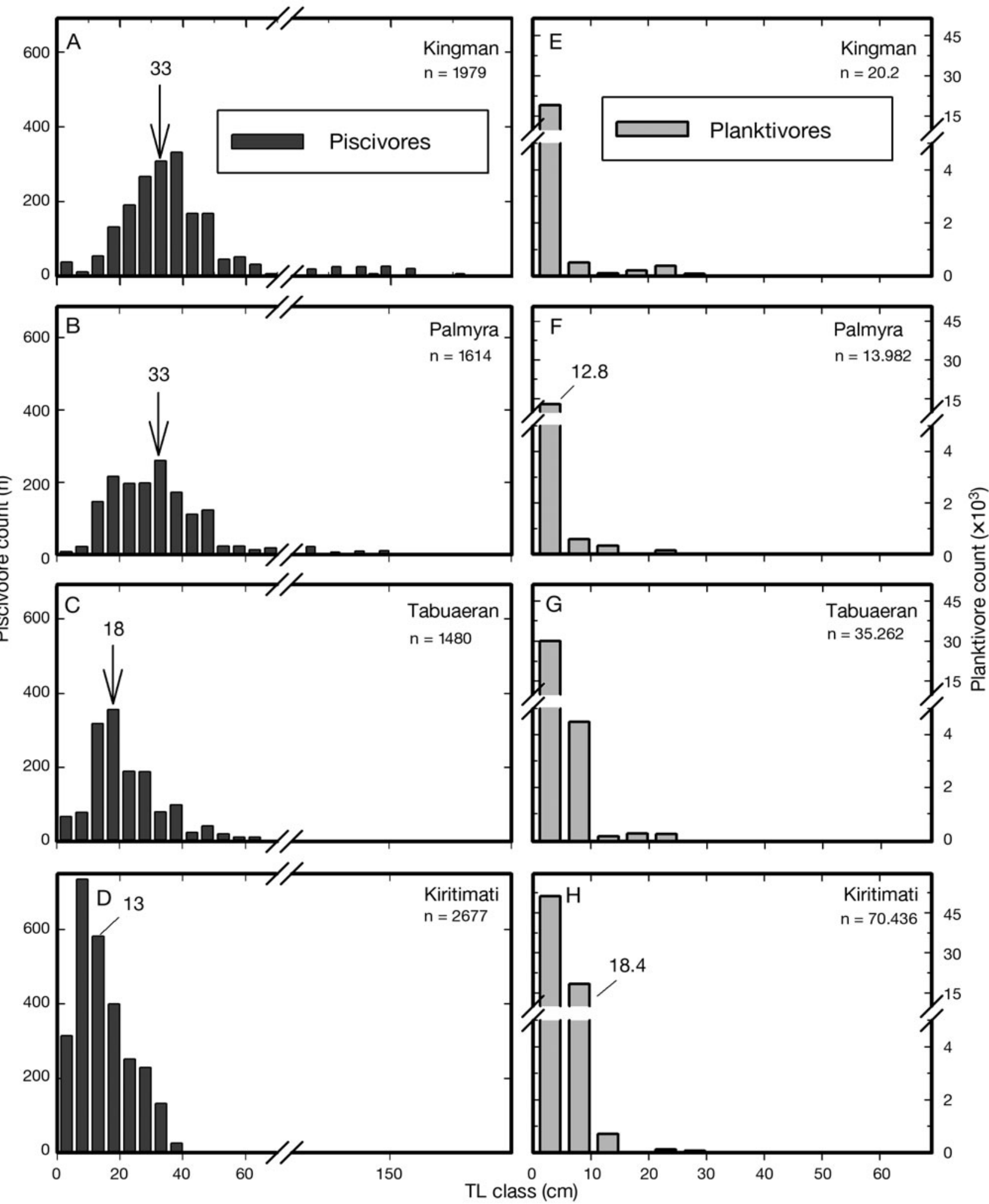

Fig. 6. Body size frequency distributions for piscivores (A-D) and planktivores (E-H) tallied at Kingman, Palmyra, Tabuaeran, and Kiritimati atolls. Dark gray: piscivores; light gray: planktivores. Note that the respective scales, including breaks, on the $x$ - and $y$-axes, are the same for each atoll within each comparison series. Numbers above bars - piscivores: median body lengths; planktivores: tallies of individuals within influential length classes. Median lengths of planktivores differed inversely to the median lengths of piscivores at the respective atoll even though the nominal median length class of planktivores was $3 \mathrm{~cm}$ total length (TL) for all atolls 


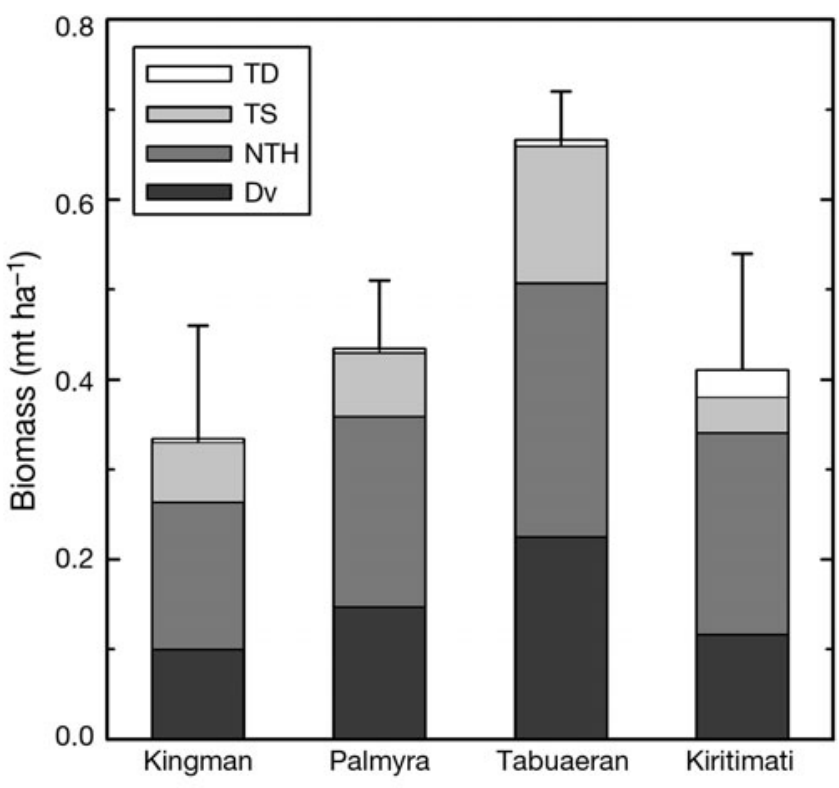

Fig. 7. Estimated mean biomass (mt ha ${ }^{-1}$ ) of primary consumers partitioned into detritivores (Dv), non-territorial herbivores (NTH), territorial surgeonfishes (TS), and territorial damselfishes (TD). Order (from left to right) follows the decreasing overall trend in fish biomass from Kingman to Palmyra to Tabuaeran to Kiritimati. Vertical bars represent $2 \mathrm{SE}$ of all primary consumer biomass

surgeonfishes and damselfishes, however, with surgeonfishes greatest at Tabuaeran-Kingman and least at Kiritimati and damselfishes greatest at Kiritimati and least at Kingman (Table 1). Territorial herbivores comprised $30 \%$ of herbivore biomass; surgeonfishes dominated ( $89 \%$ ) the biomass of territorial herbivores and averaged 10-fold larger body size than damselfishes.

Biomass of secondary consumers (pooled planktivores and benthic invertebrate-feeders, the latter group hereafter called 'benthivores') differed weakly between the 2 pairs of atolls, and was greater at the exploited $\left(0.7 \mathrm{mt} \mathrm{ha}^{-1}\right)$ pair than at the unexploited (0.5 $\mathrm{mt} \mathrm{ha}^{-1}$ ) pair (Table 1). Separating functional groups within secondary consumers also revealed more distinct patterns across atolls. Consistent with the aggregate group, the biomass of benthivores was higher at Kiritimati and Tabuaeran relative to Palmyra and Kingman. However, planktivore biomass was lowest at Palmyra and indistinguishable among the other 3 atolls. The numbers of benthivores and planktivores were distributed similarly, each being greatest at Kiritimati, followed by Tabuaeran, and least at Palmyra and Kingman (Table 1).

More focused inspection of relative changes in the planktivore guild reveals their dominant position in the restructuring of fish assemblages across the archipelago. Planktivores represented 79 and $26 \%$ of total fish numbers and biomass, respectively, at Kiritimati, compared to 73 and $6 \%$ at Kingman. The abundance and biomass of planktivores were lowest at Kingman, whereas the fraction of planktivore individuals $\leq 5 \mathrm{~cm}$ (94\%) at Kingman was highest among the 4 atolls and $21 \%$ greater than at Kiritimati, where the fraction $\leq 5 \mathrm{~cm}$ long was lowest (Fig. 6e-h). The median body size of planktivores was larger at Kiritimati than at Kingman and Palmyra (Table 1). The planktivore size patterns are not confounded by biogeographic variations in species composition: patterns remained the same when species whose distributions are biased or restricted to either pair of atolls were deleted. Of the latter, $85 \%$ were 4 species of tiny anthiines (Pseudanthias bartlettorum, P. cooperi, P. dispar, Luzonichthys whitleyi) and 1 schooling pomacentrid (Lepidozygus tapeinosoma). Planktivore size distributions persisted as disproportionately weighted toward the $<5 \mathrm{~cm}$ size class at Palmyra and Kingman when based only on the remaining species (Table 1).

\section{Trophic patterns and extraction}

Geographic patterns of fish extraction within Kiritimati atoll are consistent with the effects of fishing on the biomass, abundance, and body sizes of fished species. The intensity of extraction at Kiritimati atoll has been greatest at reef locations closest to London, the largest human settlement there (K. Anderson pers. comm.). Spearman's rank correlations between distance to London and the estimated biomass and median body lengths of piscivores and of planktivorous prey fishes bear this out. Overall, the biomass and median body sizes of piscivores were greater, whereas biomass and body sizes of planktivores (major prey of piscivorous fishes on central Pacific reefs; Kulbicki et al. 2005) were smaller, at distances farther from London (Kendall's coefficient of concordance: $W=0.827$ and 0.829 , respectively; both $\mathrm{p}<0.025)$. The biomass and body sizes of primary consumers and benthivores, untargeted by fishers compared to piscivores, were generally unrelated to distance from London $\left(\mathrm{r}_{\mathrm{s}}=-0.32\right.$ to 0.26 ; all $p \geq 0.11$ ). Because London is situated proximal to a major pass through the barrier reef (and hence distance from stations to London might be confounded by distance to pass), we further compared fish biomass and body sizes among stations at uninhabited Kingman and used Spearman's ranks to correlate these metrics versus distance from La Paloma Pass, the major pass at this atoll. Unlike Kiritimati, the biomass $(p=0.70)$ and body lengths $(p=0.29$ ) of piscivores and lengths of planktivores $(p \approx 1.0)$ at Kingman were unrelated to distance from the pass even though the biomass of planktivores was greater $\left(r_{s}=-0.47 ; p=0.02\right)$ nearer the pass. 


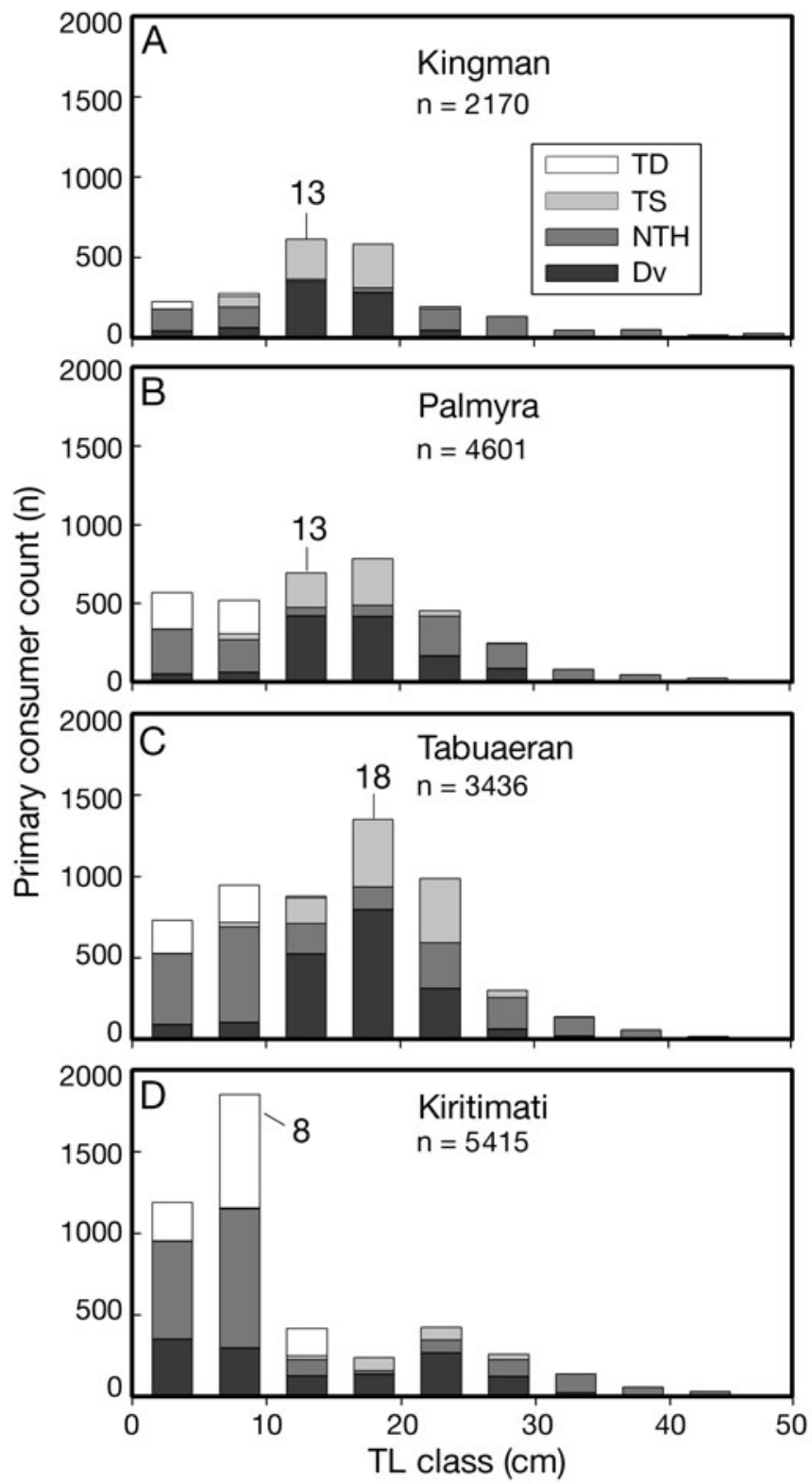

Fig. 8. Body size frequency distributions for trophic guilds (detritivores, Dv; non-territorial herbivores, $\mathrm{NTH}_{\text {; territorial }}$ surgeonfishes, TS; territorial damselfishes, TD) within primary consumers tallied at (A) Kingman, (B) Palmyra, (C) Tabuaeran, and (D) Kiritimati atolls. Numbers above bars: median body lengths (total length, TL) of pooled primary consumers

Station-specific estimates of species similarities cluster strongly by atoll for biomass if the estimates for total fishes are recast as nMDS plots. Within-atoll concordance of station estimates was lower at Tabuaeran and (especially) Kiritimati, the 2 fished atolls, versus the 2 unfished atolls (ANOSIM of pairwise comparisons between atolls; $\mathrm{R}=0.44$ to 0.94 , global $\mathrm{R}=0.69$, all $\mathrm{p}<$ 0.001). Concordance further varied geographically within Kiritimati, depending on proximity to the human population center at London. The magnitude of the Bray-Curtis similarity index that provided input to the nMDS station-separation statistic was positively related to distance from London for both piscivore and planktivore biomass, and significantly so for planktivores $\left(\mathrm{r}_{\mathrm{s}}=0.45, \mathrm{p}=0.02\right)$, indicating that among-station variation in the specific composition of biomass was greater where fishing was more intense, closer to London. The overall structure of fish assemblages was more heterogeneous across space at fished versus unfished reefs.

\section{Size at color change in parrotfishes}

Median body sizes at color-phase (sex) change were remarkably consistent with our expectations (based on inferred spatial patterns of fishing on piscivores and release of parrotfish as prey) for all species of parrotfishes that we could adequately evaluate. Of the 15 species of parrotfishes encountered during the surveys, 4 (bullethead Chlorurus sordidus, bridled Scarus frenatus, tricolor $S$. tricolor, and redlip $S$. rubroviolaceus) were sufficiently common and abundant at each of the 4 atolls to enable comparisons of sizes of color-changed individuals among atolls. For each of these 4 species, body sizes of color-changed terminal males were consistently larger proceeding from Kingman to Kiritimati. Sizes of terminal males were invariably smallest at Kingman and largest at Kiritimati (Fig. 9) and varied in concert with the overall size distribution of the respective species at each atoll (Table 1). Since size at sex change in protogynous scarids can be influenced by social factors related to density, we evaluated whether the numbers of these parrotfishes varied in a consistent manner with patterns of size-at-phase change. Abundances of tricolor and redlip parrotfishes were indistinguishable among atolls ( $p=0.13$ and 0.71 , respectively). Numbers of bullethead parrotfish were greatest at Palmyra and least at Kingman ( $p<0.001)$ despite exhibiting equally small sizes-at-phase change at both atolls. The densities of bridled parrotfish were greatest at Tabuaeran and next to least at Kiritimati ( $p=0.004$ ) despite equally large sizes-at-phase change at these 2 atolls. Thus the varying sizes at sex change of these parrotfishes cannot simply be attributed to among-atoll variations in their densities. Rather, the pattern of size at sex change observed is consistent with that observed previously in the NWHI. Protogynous parrotfishes that are the prey of apex predators change from initial phase (IP) to TP at larger body sizes where apex predators have been fished down and natural cropping is less intense, resulting in right-shifted (larger) body size distributions of parrotfish prey populations (DeMartini et al. 2005). 

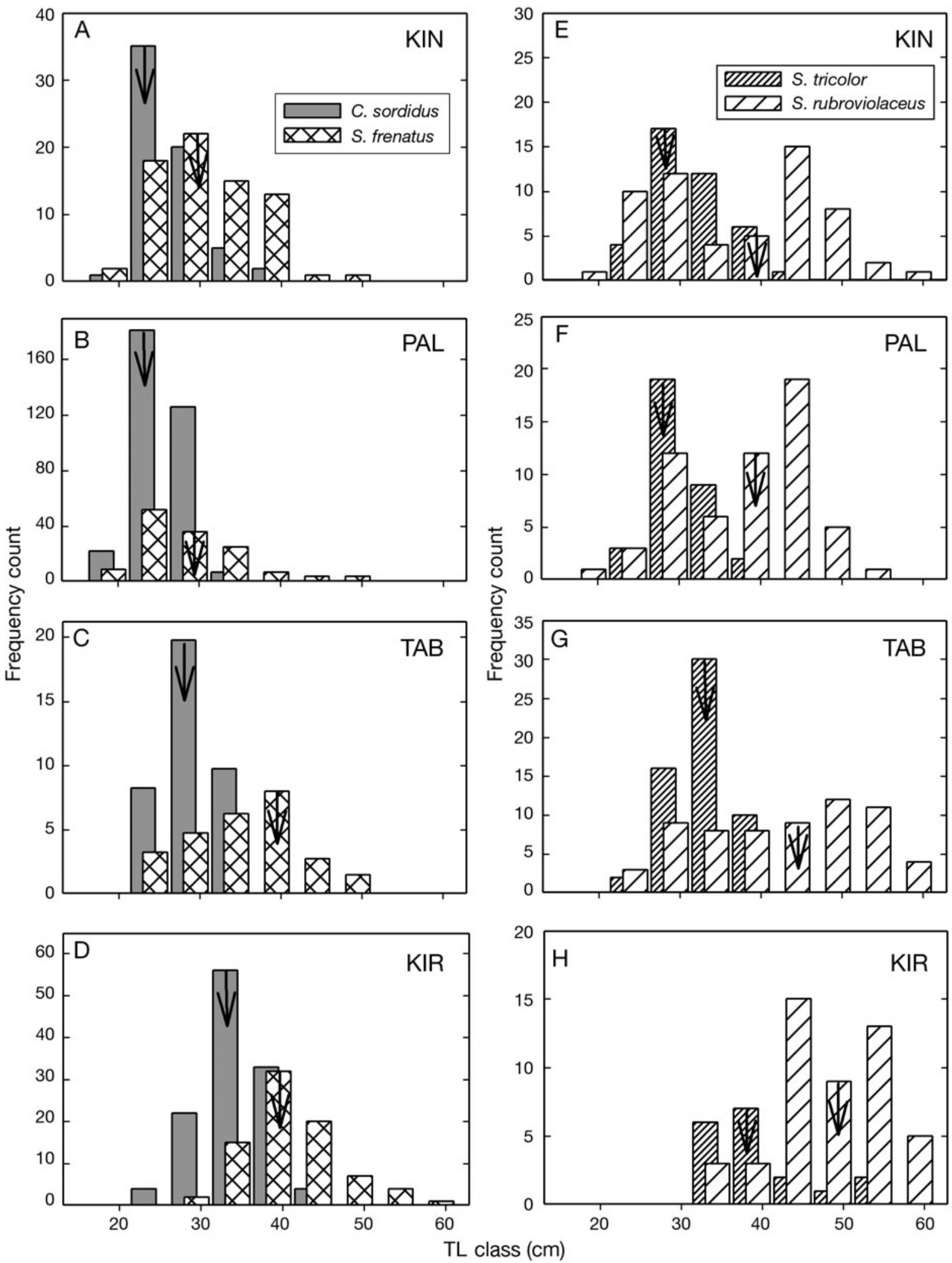

Fig. 9 Chlorurus sordidus, Scarus frenatus, S. tricolor and S. rubroviolaceus. Body size (total length, TL) frequency distributions of terminal phase (TP) individuals for each of the 2 most common and abundant parrotfishes (bullethead, bridled; panels A-D) at Kingman (KIN), Palmyra (PAL), Tabuaeran (TAB), and Kiritimati (KIR) atolls. TL frequencies are similarly depicted for the third and fourth most common and abundant parrrotfishes (tricolor, redlip) in panels E-H. Arrows indicate median body size 


\section{DISCUSSION}

Fish assemblages spanning the northern Line Islands archipelago exhibited dramatic differences in structure. Virtually pristine Kingman atoll had an enormous fish biomass, and the assemblage was overwhelmingly dominated by large piscivores (mostly sharks up to $>2 \mathrm{~m}$ in length and snappers). At the other end of the gradient, Kiritimati atoll had greater fish numbers than Kingman, but biomass was 5 times lower, and the assemblage was dominated by smallbodied species belonging to lower trophic levels, especially planktivores.

\section{Direct effects of extraction}

Our observations of gradients in total standing biomass, piscivore dominance, body size composition, and fish assemblage structure are most consistent with expectations based on the exploitation gradient. Numerous studies attest to reductions in top trophic level and overall standing biomass and related shifts to average smaller sizes and lower trophic levels that result from fishing down predatory reef fishes (Friedlander \& DeMartini 2002, Ackerman et al. 2004, Hawkins \& Roberts 2004b, Schroeder et al. 2006). At the most heavily fished atoll (Kiritimati), the fish assemblage-exploitation gradient observed among atolls is further supported by spatial patterns of correlation between a realistic proxy for extraction intensity (distance from human population center) and assemblage modification within the atoll. Piscivore and planktivore biomass and body sizes varied inversely with distance from the atoll's major population center. Data for Kingman show that the spatial effect at Kiritimati is not simply due to a confounding correlation between human habitation and proximity to the reef pass. Despite declines in planktivore biomass with distance from the reef pass at Kingman (likely due to greater plankton availability in passes), no correlated changes in piscivore density or body size paralleled those observed at Kiritimati. Presumed fishing effects also were not an artifact of the spatial design of our surveys, as there was no spatial pattern to the distribution of fish biomass among the stations surveyed at Kingman atoll (2-way ANOVA on total biomass, northern versus southern exposure effect: $F_{1,23}=1.22, \mathrm{p}=$ 0.28 ; least squares regression of biomass on distance from most exposed station: $\mathrm{r}^{2}=0.008, F_{1,23}=0.19, \mathrm{p}=$ $0.66)$. This would not have been the case if windward and leeward sides at an undisturbed atoll like Kingman differed appreciably in secondary production, which the absence of surveys on the windward side of Kiritimati might otherwise leave open to question.

\section{Generality of piscivore patterns}

The decline of apex predators that we observed across the gradient seems clearly related to fishing, as attested by the correlation between fishing pressure and piscivore abundance both within and among atolls. In addition, historical records prior to the onset of industrial fishing reported abundant shark populations throughout the region, as summarized by Sandin et al. (2008). Accounts from 18th and 19th century explorers and whalers visiting Kiritimati specifically attest to a great abundance of sharks and other large piscivores dominating the lagoon and fore reef habitats in the past. In more recent times, large snappers and grey reef sharks have been conspicuously abundant at Kingman and Palmyra on dive surveys conducted by the NOAA Fisheries Service during 2001, 2002, and 2004. During these same NOAA cruises, grey reef sharks also were conspicuously abundant at Howland, Baker, and Jarvis Islands, which are all uninhabited, low-latitude $\left(0.35^{\circ} \mathrm{S}\right.$ to $\left.0.8^{\circ} \mathrm{N}\right)$, non-atoll Phoenix and Line Island possessions of the United States, located in the same xeric climatic zone and region of equatorial upwelling as Kiritimati (Brainard et al. 2005). In general, other environmental factors that differ among these atolls, such as latitude, rainfall, upwelling, and planktonic productivity (chlorophyll), are unrelated to the among-atoll differences in the standing biomass and assemblages of fishes that we observed. High total fish biomass and disproportionately great representation of piscivores is pervasive across all of these lower latitude $\left(<2^{\circ}\right)$ reefs except Tabuaeran and Kiritimati, despite striking similarities in elevated planktonic productivities among all that occur within the region of equatorial upwelling (Sandin et al. 2008). Our observations provide the detail needed at an expanded spatial scale to conclusively demonstrate patterns of piscivore dominance and the trophic structuring of fish assemblages suggested by the preliminary study of Stevenson et al. (2007) in the northern Line Islands.

\section{Indirect effects of extraction}

Piscivorous reef fishes can affect the abundance and body size distribution of their prey (see Connell 1998, Graham et al. 2003), although the extent to which this occurs and its influence on prey population dynamics are poorly understood (Hixon \& Jones 2005). In this study, we document some suggestive, indirect community-level responses to changes in piscivore dominance. Planktivorous prey fishes showed a dramatic decline in abundance, biomass, and body size from the most-exploited Kiritimati to the least-exploited King- 
man. This pattern is similar within Kiritimati, with biomass and body size decreasing with distance from the center of human population and fishing effort. Differences among atolls in the absolute and relative abundances and size composition of territorial surgeonfishes and damselfishes also might help explain some striking differences among atolls in algae and corals (Sandin et al. 2008); the size structure of territorial herbivores importantly influences their interactions and benthic community dynamics (Robertson 1998, Ceccarelli et al. 2006). The smaller size at sex change in parrotfishes at Palmyra-Kingman is consistent with an indirect response to reduced piscivory by top predators (DeMartini et al. 2005), although it might represent a response to some environmental gradient (Gust et al. 2002, Gust 2004), or both. We cannot discriminate between these possibilities because body size at sex change tracked overall size distribution of the respective parrotfish species at each atoll. The among-atoll patterns in planktivore body sizes and parrotfish size at sex change should not be confused with the leftskewed (smaller) size distribution of the benthivore consumer guild, which (together with the more obvious reduction in piscivore stocks) likely represent direct responses to human extraction at KiritimatiTabuaeran.

An evaluation of patterns for corals and algae as well as fishes does not indicate a trophic cascade (Sandin et al. 2008). Our results nonetheless suggest that the effects of reduced densities of top predators propagate across trophic levels and cause changes in the trophic structure of the assemblage, including an increase in the spatial variability of such structure (greater amongstation variation in biomass at Tabuaeran and Kiritimati as indicated by nMDS and ANOSIM analyses).

Our observations of strong indirect effects of piscivores on secondary consumers differ from those of Stevenson et al. (2007), who did not detect such effects based on a limited and variable number of transects conducted in different years at Palmyra, Tabuaeran, and Kiritimati only. Low statistical power likely explains why among-atoll differences in secondary consumer biomass were not detected.

The greater standing stocks at Kiritimati of the smallbodied darkfin hind, and perhaps several other lesstargeted (bluestriped snapper) and untargeted (blackside and halfspotted hawkfishes) fishes, all of which are residential and smaller-bodied piscivores, might represent competitive release as another type of indirect response to human extraction. Competitive release has been documented in other marine systems, both in response to natural phenomena (Schmitt \& Holbrook 1990) and as a result of fishing (Fogarty \& Murawski 1998). Despite increases in smaller-bodied piscivores from Kingman to Kiritimati, the pattern of total piscivore biomass is driven by the biomass of large-bodied apex predators, which decreases dramatically between Kingman and Kiritimati. Such differences in piscivore assemblages would invariably affect realized levels and types of predatory threats for prey at these atolls. Results like this should be seriously considered when designing future studies of predation effects on degraded reefs dominated by small-bodied piscivores, especially tempering selection-based arguments regarding reef fish behavior and demography.

The indirect responses to release from apex predation might extend to lower trophic levels as well (via apex predation on herbivores like parrotfishes). A suggestively higher standing biomass of primary consumers at Tabuaeran, including detritivores as well as herbivores, might be related either to increased sedimentation or a greater biomass of algae at Tabuaeran (Sandin et al. 2008) as bottom-up effects. Our observation that Tabuaeran had the highest biomass of herbivores might be interpreted as a bottom-up consequence of algae released from competition with corals, with lower cover of the latter resulting from an environmental impact like bleaching (Williams \& Polunin 2001). Evaluating piscivore effects on herbivores is problematic. Certainly, distinguishing cause from effect is less straightforward for primary consumers eaten by apex predators.

In contrast to the pattern described here, Stevenson et al. (2007) reported an increase of herbivore biomass from Kiritimati to Palmyra. They noted that this pattern is consistent with direct exploitation by humans of all trophic levels only on the inhabited atolls, similar to results from the Bahamas (Mumby et al. 2006). Because fish were surveyed in different habitats across atolls (back reef on Palmyra and shallow fore reef on Kiritimati and Tabuaeran; Stevenson et al. 2007), the observed pattern could also reflect herbivore habitat specificity. The effects of extraction of herbivores on Kiritimati and Tabuaeran also may be very habitat specific, e.g. greatest on the most accessible shallow reefs.

\section{Inverted biomass pyramids}

Data collected at the 2 little-disturbed atolls (Kingman, Palmyra) provide insights into natural fish assemblage structure on central Pacific atolls. Fish trophic structure at Kingman, where the biomass densities of tertiary consumers (apex predators and other piscivores) were more than 5-fold greater than those of all lower-trophic levels pooled, clearly represents an example of an inverted biomass pyramid. Strongly inverted biomass pyramids like that observed at Kingman (and, to a lesser extent at Palmyra, where piscivorous fish biomass was still twice as large as that of 
lower trophic level fishes) are not only theoretically possible (Ballantyne 2004, Brown et al. 2004) but have been empirically documented in other reef ecosystems (e.g. Friedlander \& DeMartini 2002). It is important to note, however, the key distinction here between biomass and production (energy flux): thermodynamic constraints require energy flux to be greater at lower relative to higher trophic levels; hence production pyramids can never be inverted as biomass pyramids can (Emlen 1973, Brown et al. 2004).

For poikilothermic consumers like fishes with often high (to $20-30 \%$ ) trophic efficiencies, biomass inversions of this magnitude seem possible based on reasonable values for the population growth, death, and turnover rate parameters of major predator and prey species (S. Sandin unpubl.). For example, the von Bertalanffy growth rate $(k)$ of twinspot snapper is estimated to be $\leq 0.2 \mathrm{yr}^{-1}$ (Marriott 2002), and its natural mortality rate, $M$ (where $M=2 k$ for lutjanids; Ralston 1987 ) is likely $\leq 0.4 \mathrm{yr}^{-1}$. The growth and natural mortality rates of most species of reef sharks are $0.1 \mathrm{yr}^{-1}$ or less (Smith et al. 1998). Most reef sharks are long-lived, slow-growing, and late-maturing with low reproductive rates (Smith et al. 1998). Both of these major taxa of predators should be extremely sensitive to fisheries extraction based on their life histories (Robbins et al. 2006). Conversely, the growth and related mortality rates of small-bodied planktivorous prey fishes, exemplified by the banana fusilier Pterocaesio pisang (not present in the northern Line Islands but typical of planktivorous caesionids), are about $1 \mathrm{yr}^{-1}$ and $2 \mathrm{yr}^{-1}$, respectively (Russ et al. 1992). The turnover (production-to-biomass, $P / B$ ) rates of species of even smallerbodied reef fishes are likely more extreme, with estimates of $Z$, the total mortality rate $(=P / B$ at population equilibrium) exceeding 5 to 6 , equivalent to finite mortality rates $\geq 99 \% \mathrm{yr}^{-1}$ (e.g. Kritzer 2002, Wilson 2004). Short-lived, lower trophic level fish thus serve as energetic shunts, converting food like plankton and algae into fish biomass, which is quickly transferred to and stored in long-lived, higher-trophic-level fish through predation. Life history parameters are generally lacking for most small-bodied reef fishes, and efforts should be made to obtain this information given their importance in understanding tropical fisheries production and reef ecosystem function.

Additional factors that can help to explain the inverted biomass pyramid may include food subsidies (Stevenson et al. 2007) from lagoon and pelagic environments. We observed a marked spatial partitioning by apex predators, with large sharks being present only on the fore reef and the lagoons acting as shark nurseries. It thus appears unlikely that the larger sharks we observed on the fore reef feed abundantly in the lagoons. Moreover, the 3 species of sharks we encountered are all reef-associated and anatomically adapted to feeding on the reef, and not on pelagic, faster-swimming fishes. A study on the feeding ecology of the apex predators at Kingman and Palmyra would shed light into the potential contribution of food subsidies to the maintenance of inverted biomasspyramids.

It is important to emphasize that when fisheries target the largest individuals of fishes like twinspot snapper and the reef sharks, these large-bodied species become particularly susceptible to over-exploitation. Data from Tabuaeran and Kiritimati support this concern, as evidenced by the stark declines in the largest species of snapper and the reef sharks. We believe it likely that the present paucity of observations of naturally inverted biomass pyramids for reef fish assemblages is an artifact of the generally impacted condition of most reefs worldwide, where reductions of apex predators have drastically altered assemblage dynamics, as observed at Tabuaeran and Kiritimati, even if all trophic levels have not yet been overfished.

\section{Baselines, management, and conservation issues}

Our estimates of at least several $\mathrm{mt} \mathrm{ha}^{-1}$ of piscivore biomass at Kingman and Palmyra should be viewed as representative of undisturbed central Pacific atolls. Several lines of evidence reinforce this belief. Historical evidence indicates that pristine food webs are very distinct from the present ones (Steele \& Schumacher 2000, Jackson et al. 2001). The same is almost certainly true of coral reef fish assemblages, although we know very little about historical changes in fish food webs as a result of the removal of large predatory fishes. This is particularly worrying because our baselines of coral reef community composition and abundance of fishes originated only a few decades ago and were based on short-term changes in community composition that ignore larger time scales. In the absence of quantitative time series, the study of gradients of exploitation and of undisturbed reefs such as Kingman is essential to fully understand the composition of coral reef communities prior to overfishing and to estimate the consequences of fishing at all spatial and temporal scales. Kingman thus represents a demonstrable baseline for Pacific reef fish assemblages and a key reference point for evaluating the efficacy of conservation efforts. Studies of reef fish assemblage structure typically suffer from the shifting baseline syndrome (Pauly 1995). Most such studies have considered gradients of predator abundance covering a biomass range that is only a small fraction of the gradient studied here (Dulvy et al. 2004, but see Newman et al. 2006), had small predators 
(Connell 1997), or never mentioned sharks (Sale 1991). Similar to our work, a recent study noted a striking contrast in the density of reef sharks between fished and unfished areas using data from in situ surveys at Australia's Great Barrier Reef and the Cocos (Keeling) Islands (Robbins et al. 2006). In sum, these findings suggest that some paradigms in reef fish ecology and conservation should be revisited.

Ideally, the mortality being added by human extraction at Tabuaeran and Kiritimati atolls needs to be reduced if populations of apex predators and larger piscivores are to recover and subsequently sustain themselves. However, because of the generally high mobility of large-bodied predatory fishes, they would seem the least likely to benefit from the establishment of spatial no-take areas that encompass an acceptably small (e.g. $20-30 \%$ ) percentage of the total area of an atoll like Kiritimati. Reducing total fishing effort through conventional fisheries management measures (like take and size limits) is unrealistic at islands like Kiritimati with expanding human populations and a cultural history of reef fish harvesting. Reasonable options for fisheries management at Kiritimati thus might include initiating spatial protection of lower trophic level fishes in multiple, small-scale no-take reserves combined with a larger, perhaps atoll-wide, prohibition against the taking of sharks and the largest snappers and groupers for a decade or longer. An encouraging first step is Kiribati's recent legislation prohibiting fishing by international fleets anywhere within the country's Exclusive Economic Zone. Kiribati's recent designation of the Phoenix Islands as the Phoenix Islands Protected Area should bring increased international attention to the region and provide opportunities for research, enforcement, and capacity building. Finally, the continued protection and support of the 2 US National Wildlife Refuges of Kingman and Palmyra should be prioritized. Intact reef communities such as these are tragically rare and serve as invaluable ecological baselines that describe what was once present in, and what is possible for, central Pacific coral reefs.

Acknowledgements. This research was supported by the Moore Family Foundation, the Fairweather Foundation, National Geographic Society, Conservation International, E. Scripps, J. Gayler, and several private donors. E.E.D. thanks the NOAA Office of Habitat Conservation and the Coral Reef Ecosystem Division of the Pacific Islands Fisheries Science Center (PIC) for general support and gratefully acknowledges travel funds awarded by NOAA Fisheries to the PIC. This work was conducted with the support of the US Fish and Wildlife Service, the Kiribati Ministry of Environment, Lands and Agriculture Development, and The Nature Conservancy. We also thank L. Wedding for crafting Fig. 1 and C. Boggs, N. Graham, J. McPherson, J. Baum, and several anonymous reviewers for constructive criticisms of the draft manuscript.

\section{LITERATURE CITED}

Ackerman JL, Bellwood DR, Brown JH (2004) The contribution of small individuals to density-body size relationships: examination of energetic equivalence in reef fishes. Oecologia 139:568-571

Almany GR (2003) Priority effects in coral reef fish communities. Ecology 84:1920-1935

$>$ Ballantyne F (2004) The relative importance of herbivory and carnivory on the distribution of energy in a stochastic tritrophic food web. J Theor Biol 226:349-357

Brainard R, Maragos J, Schroeder R, Kenyon J and others (2005) The state of coral reef ecosystems of the Pacific Remote Island Areas. In: Waddell J (ed) The state of coral reef ecosystems of the United States and Pacific Freely Associated States: 2005. NOAA Tech Mem NOS NCCOS, Honolulu, HI, p 338-372

Brown JH, Gillooly JF, Allen AP, Savage VM, West GB (2004) Toward a metabolic theory of ecology. Ecology 85: 1771-1789

Ceccarelli DM, Hughes TP, McCook LJ (2006) Impacts of simulated overfishing on the territoriality of coral reef damselfish. Mar Ecol Prog Ser 309:255-262

Clarke KR, Gorley RN (2006) PRIMER v6: user manual/tutorial. PRIMER-E, Plymouth

Connell SD (1997) The relationship between large predatory fish and recruitment and mortality of juvenile coral-reef fish on artificial reefs. J Exp Mar Biol Ecol 209:261-278

Connell SD (1998) Effects of predators on growth, mortality and abundance of a juvenile reef-fish: evidence from manipulations of predator and prey abundance. Mar Ecol Prog Ser 169:251-261

DeMartini EE, Friedlander AM, Holzwarth SR (2005) Size at sex change in protogynous labroids, prey body size distributions, and apex predator densities at NW Hawaiian atolls. Mar Ecol Prog Ser 297:259-271

> Dinsdale EA, Pantos O, Smriga S, Edwards RA and others (2008) Microbial ecology of four coral atolls in the northern Line Islands. PLoS One 3(2):e1584

Dulvy NK, Freckleton RP, Polunin NVC (2004) Coral reef cascades and the indirect effects of predator removal by exploitation. Ecol Lett 7:410-416

Emlen JM (1973) Ecology: an evolutionary approach. Addison-Wesley, Reading, PA

> Fogarty MJ, Murawski SA (1998) Large-scale disturbance and the structure of marine systems: fishery impacts on Georges Bank. Ecol Appl 8:S6-S22

> Friedlander AM, DeMartini EE (2002) Contrasts in density, size, and biomass of reef fishes between the northwestern and the main Hawaiian Islands: the effects of fishing down apex predators. Mar Ecol Prog Ser 230:253-264

Gove J (20008) Climate, oceanography, and ocean currents in the central Pacific. In: Maragos J, Miller J, Gove J, DeMartini $\mathrm{E}$ and others (eds) US coral reefs in the Line and Phoenix Islands, central Pacific Ocean: history, geology, oceanography, and biology. In: Riegl B, Dodge RE (eds) Coral reefs of the USA. Coral reefs of the world, Vol 1. Springer-Verlag, Heidelberg, p 595-641

Graham NAJ, Evans RD, Russ GR (2003) The effects of marine reserve protection on the trophic relationships of fishes on the Great Barrier Reef. Environ Conserv 30:200-208

Graham NAJ, Dulvy NK, Jennings S, Polunin NVC (2005) Size spectra as indicators of the effects of fishing on coral reef fish assemblages. Coral Reefs 24:118-124

Gust N (2004) Variation in the population biology of protogynous coral reef fishes over tens of kilometers. Can J Fish Aquat Sci 61:205-218 
Gust N, Choat J, Ackerman J (2002) Demographic plasticity in tropical reef fishes. Mar Biol 140:1039-1051

- Hawkins JP, Roberts CM (2004a) Effects of fishing on sex-changing Caribbean parrotfishes. Biol Conserv 115: $213-226$

Hawkins JP, Roberts CM (2004b) Effects of artisanal fishing on Caribbean coral reefs. Conserv Biol 18:215-226

Hixon MA, Jones GP (2005) Competition, predation, and density-dependent mortality in demersal marine fishes. Ecology 86:2847-2859

Jackson JBC, Kirby MX, Berger WH, Bjorndal KH and others (2001) Historical overfishing and the collapse of coastal ecosystems. Science 293:629-637

Kritzer JP (2002) Stock structure, mortality and growth of the decorated goby, Istigobius decoratus (Gobiidae), at Lizard Island, Great Barrier Reef. Environ Biol Fish 63:211-216

Kulbicki M, Bozec YM, Labrosse P, Letourneur Y, Mou-Tham G, Wantiez L (2005) Diet composition of carnivorous fishes from coral reef lagoons of New Caledonia. Aquat Living Resour 18:231-250

Manly BFJ (1991) Randomization and Monte Carlo methods in biology. Chapman \& Hall, London

Marriott RJ (2002) Age, growth and sex structure of red bass populations on the Great Barrier Reef. In: Williams AJ, Welch DJ, Muldoon G, Marriott RJ, Kritzer JP, Adams S (eds) Bridging the gap: a workshop linking student research with fisheries stakeholders. CRC Reef Res Cent Tech Rep No 48, Townsville, p 81-86

Mumby PJ, Dahlgren CP, Harborne AR, Kappel CV and others (2006) Fishing, trophic cascades, and the process of grazing on coral reefs. Science 311:98-101

Newman MJH, Paredes MA, Sala E, Jackson JBC (2006) Structure of Caribbean coral reef communities across a large fishing gradient of fish biomass. Ecol Lett 9: 1216-1227

Pauly P (1995) Anecdotes and the shifting baseline syndrome. Trends Ecol Evol 10:430

Platten JR, Tibbetts IR, Sheaves MJ (2002) The influence of increased line-fishing mortality on the sex ratio and age of sex reversal of the venus tusk fish. J Fish Biol 60:301-318

Ralston S (1987) Mortality rates of snappers and groupers. In: Polovina JJ, Ralston S (eds) Tropical snappers and groupers: biology and fisheries management. Westview Press, Boulder, CO, p 375-404

Robbins WD, Hisano M, Connolly SR, Choat JH (2006) Ongoing collapse of coral-reef shark populations. Curr Biol 16:2314-2319

Robertson DR (1998) Implications of body size for interspecific interactions and assemblage organization among coralreef fishes. Aust J Ecol 23:252-257
Rochet MJ, Trenkel VM (2003) Which community indicators can measure the impact of fishing? A review and proposals. Can J Fish Aquat Sci 60:86-99

Russ GR, Alcala AC, Cabanban AS (1992) Marine reserves and fisheries management on coral reefs with preliminary modeling on the effects of yield per recruit. In: Richmond RH (ed) Proc 7th Int Coral Reef Symp, 22-26 June 1992, Guam. University of Guam Press, Mangilao, p 978-985

Sackley PG, Kaufman LS (1996) Effect of predation on foraging height in a planktivorous coral reef fish, Chromis nitida. Copeia 3:726-729

Sale PF (1991) The ecology of fishes on coral reefs. Academic Press, San Diego, CA

Sandin SA, Smith JE, DeMartini EE, Dinsdale E and others (2008) Baselines and degradation of coral reefs in the northern Line Islands. PLoS One 3(2):e1548

SAS Institute (2004) SAS/STAT ${ }^{\circledR} 9.1$ user's guide. SAS Institute, Cary, NC

Schmitt RJ, Holbrook SJ (1990) Population responses of surfperch released from competition. Ecology 71:1653-1655

Schroeder RE, Trianni MS, Moots KA, Laughlin JL, Zgliczynski BH, Tibbetts RB (2006) Status of fishery target species on coral reefs of the Marianas Archipelago. In: Suzuki Y, Nakamori T, Hidaka M, Kayanne $\mathrm{H}$ and others (eds) Proc 10th Int Coral Reef Symp, 28 June-2 July 2004, Japanese Coral Reef Society, Tokyo, p 1016-1027

Siegel S, Castellan JJ Jr (1988) Nonparametric statistics for the behavioral sciences, 2nd edn. McGraw-Hill, New York

Smith SE, Au DW, Show C (1998) Intrinsic rebound potentials for 26 species of Pacific sharks. Mar Freshw Res 49: $663-678$

Sokal RR, Rohlf FJ (1981) Biometry: the principles and practice of statistics in biological research, 2nd edn. WH Freeman, San Francisco, CA

Steele JH, Schumacher M (2000) Ecosystem structure before fishing. Fish Res 44:201-205

Stevenson C, Katz LS, Micheli F, Block B and others (2007) High apex predator biomass on remote Pacific islands. Coral Reefs 26:47-51

Warwick RM, Clarke JR (1994) Relearning the ABC: taxonomic changes and abundance/biomass relationships in disturbed benthic communities. Mar Biol 118: 739-744

Webster MS, Almany GR (2002) Positive indirect effects in a coral reef fish community. Ecol Lett 5:549-557

Williams ID, Polunin NVC (2001) Large-scale associations between macroalgae cover and grazer biomass on middepth reefs in the Caribbean. Coral Reefs 19:358-366

Wilson SK (2004) Growth, mortality and turnover rates of a small detritivorous fish. Mar Ecol Prog Ser 284:253-259
Editorial responsibility: Charles Birkeland,

Honolulu, Hawaii, USA
Submitted: October 10, 2007; Accepted: May 27, 2008

Proofs received from author(s): July 15, 2008 